\title{
DE LA REVISIÓN DE LAS CONSTITUCIONES: CONSTITUCIONES NUEVAS Y VIEJAS
}

\author{
JAVIER GARCÍA ROCA \\ Catedrático de Derecho Constitucional \\ Universidad Complutense de Madrid
}

En recuerdo de Pablo Santolaya, alter ego...

\section{SUMARIO}

I. Una teoría de una constitución realizada. II. La reforma como decisión política y su conformación jurídica III. Los defectos de una constitución. IV. El pacto constitucional que mantiene una constitución escrita: las condiciones materiales. V. La tensión entre estabilidad y dinámica constitucionales. Constituciones viejas y nuevas. VI. Pluralismo de constituciones: el impacto del constitucionalismo de la integración. VII. Consideraciones finales.

\section{UNA TEORÍA DE UNA CONSTITUCIÓN REALIZADA}

Teoría especial. Esbozaré algunas proposiciones sobre la revisión de las constituciones. Me pregunto si cabe una teoría general de la reforma constitucional o, por el contrario, es precisa una explicación concreta de una realidad histórica ${ }^{1}$, regulada por normas fundamentales en unas coordenadas de tiempo y espacio. Probablemente, sólo una teoría especial de la reforma permite explicar las cosas, dada las diferencias entre modelos constitucionales y Estados con tradiciones y culturas muy diversas.

Reflexión general. Pero esto no quiere decir que no se pueda hacer una reflexión general en un contexto comparado. Porque el constitucionalismo liberal-democrático es un movimiento cultural, ilustrado, que comparte un conjunto de categorías y principios comunes, y que no conoce fronteras. Es previsible un flujo de

1 Cfr. Hesse, K.: Escritos de Derecho Constitucional, Centro de Estudios Constitucionales, Madrid, 1983, afirma que la «concretización» del contenido de una constitución reclama un proceso de realización, incorporar las circunstancias de la realidad: una constitución realizada, pp. 3-31. 
influencias recíprocas entre las obras generales y una multiplicidad de partes especiales en cada Estado. Los problemas del constitucionalismo tienden a ser los mismos, aunque no sean iguales las soluciones. Pero existe un claro riesgo de levedad en cualquier reflexión general al ubicarse fuera de la historia.

Cuestiones principales y accesorias. Claro está que no puedo hacer un tratado sobre la reforma, desecho la idea de abordar los temas más frecuentes. Hay cuestiones accesorias, que siguen a la cosa principal, pese a que hasta ahora han centrado casi con exclusividad las preocupaciones doctrinales. No me ocupare de los controles de constitucionalidad de las reformas constituciona$\operatorname{les}^{2}$, y sólo mencionaré los límites a la reforma ${ }^{3}$, aspectos que creo accesorios de los principales y estimo cuestiones ya muy estudiadas ${ }^{4}$. Tampoco afrontaré con detalle la regulación de los procedimientos, si bien mis propuestas sugieren unos procedimientos agravados respecto de las leyes, pero no mucho, para permitir un uso normalizado. El pensamiento jurídico sobre la reforma debe actualizarse. Los problemas esenciales no son los límites a la revisión ni los controles sino antes bien cuándo debe acometerse la reforma, con qué frecuencia, cómo y por quién. Conviene volver al principio. Aquellos asuntos son accesorios de éstos, pese a que los hemos dado por supuestos desde hace demasiado tiempo. Algo que no hicieron clásicos como Bryce en el XIX ${ }^{5}$ y, un siglo después, Wheare ${ }^{6}$, quienes abordaron la rigidez y, al hilo de ella, una verdadera teoría de la constitución ${ }^{7}$.

Reformas o mutaciones. Como segunda delimitación del objeto, partiré de la summa divisio entre reformas constitucionales, modificaciones formales del texto de

2 Es clásico P. de VEgA: La reforma constitucional y la problemática del poder constituyente, epígrafe 4 «Los límites y controles a la reforma constitucional», Tecnos, Madrid,1985. Puede leerse Díaz Ricci, S.: Teoría de la reforma constitucional, UNAM-UCM-EDIAR, Buenos Aires, 2004, cap. V «Control de constitucionalidad de la reforma».

3 Cfr De Vega, P.: ob.cit. Aláez, B.: Los límites materiales a la reforma de la Constitución española de 1978, CEPC, Madrid, 2000. Entre otros, RAMírez, G.: Los límites a la reforma constitucional y las garantías-limites del poder constituyente, IEC Carlos Restrepo, Bogotá, 2003.

4 Una referencia es Pérez Royo, J. : La reforma de la Constitución, Congreso de los Diputados, Madrid, 1987, tiene interés su análisis de la reforma en la tradición americana y europea. Véase DíAz Ricci, S.: Teoría de la reforma constitucional, ob.cit., Caps. II y III.

5 Debo reconocer la profunda huella de J. BRYCE. Entre otros estudios: Constituciones flexibles y constituciones rígidas, Centro de Estudios Constitucionales, Madrid, 1988, con estudio preliminar de LuCAS Verdú, P. Las citas posteriores son de esta versión. Hay una nueva edición en 2015 en la que se ha revisado la traducción con prólogo de Lucas Murillo De La Cueva, P. Hubo una $1^{\text {a }}$ edición del IEP, si bien he manejado la $2^{\text {a de }} 1962$ cuyo prólogo advierte el impacto vertical y horizontal de la obra entre la doctrina y la opinión de la época, particularmente, en MORET, S. El texto original es una conferencia de 1884 publicada más tarde «Flexible and Rigid Constitutions» en Studies in History and Jurisprudence, vol. I, Clarendon Press, Oxford, 1901, pp. 145 y ss. BRYCE volvió al tema en varios trabajos y escribió siempre en un inglés claro, suasorio y elegante.

6 K.C. WHEARE: Las constituciones modernas, Editorial Labor, $2^{\mathrm{a}}$ ed. 1975, editado en inglés en 1966. Un australiano, profesor de Oxford y experto en las constituciones de la Commonwealth.

7 En el mismo sentido, el estudio previo de Lucas Verdú, P. a Bryce, J.: ob.cit., p. XVII y ss. También el posterior prólogo de Lucas Murillo De La Cueva, P. p. XII. 
las disposiciones escritas de una constitución, y mutaciones constitucionales ${ }^{8}$. Las mutaciones son cambios en las exégesis de las normas fundamentales que no modifican el texto de las disposiciones escritas, pero que crean nuevas normas en virtud de interpretaciones constitucionales sobrevenidas en la jurisprudencia o en los desarrollos legales o en la realidad. Dada la apertura de las normas constitucionales, las mutaciones pueden conducir a resultados distintos ante supuestos de hecho cambiantes en un proceso de especificación o «concretización»?

Mutación y pluralismo de constituciones. También acontecen mutaciones en virtud de normas que emanan de otros ordenamientos en el actual escenario de pluralismo de constituciones. El Convenio Europeo de Derechos Humanos y la análoga Convención Americana y el Derecho de la Unión han producido a veces verdaderas mutaciones constitucionales, y no meros complementos o desplazamientos de las normas internas en favor de la protección más intensa o de la primacía del Derecho Europeo. Son varios los ejemplos, por más que algunos Estados se resistan a aceptarlo, acantonándose en un entendimiento absoluto de la idea de soberanía que no se corresponde ya con la realidad ni con unos procesos de transferencia de competencia o cesión de soberanía.

Las reformas como objeto. Pero me ocuparé sólo de las reformas, aunque las mutaciones sean muy frecuentes en nuestros días, dada la constante expansión de las jurisdicciones constitucionales y convencionales, porque tienen ya buenos estudios desde las obras clásicas de Laband, Jellinek y Hsü Dau-Lin ${ }^{10}$, y un relevante número de autores contemporáneos ${ }^{11}$.

8 García Pelayo, M. tradujo Verfassungswandel como «mutación», pero Wandlung, además de «cambio», significa la «transubstanciación» que se produce en la eucaristía según la teología, al igual que en las normas constitucionales ocurre según advierte LuCAS Verdú, P. en su estudio previo a DAU-LiN, H.: Mutación de la Constitución, IVAP, Oñate, 1999, traducción de LuCAS Verdú, P. y Förster, Ch., original en alemán de 1932

9 Hesse, K. : ob.cit., p. 25

10 Cfr el pionero trabajo de P. LABAnd: Die Wandlungen der Deutschen Reichsverfassung, Dresden, Zahn u. Jaensch, 1895. He usado G. JellineK: Reforma y mutación de la Constitución, CEC, Madrid, 1991, traducción de Christian Förster, y estudio preliminar de P. LuCas Verdú, el original en alemán de 1906. Un comentario es A. V. SÁNChEZ URrutia: «La fuerza de la constitución y la constitución de la fuerza» en REDC, $\mathrm{n}^{\circ} 37,1993$, p. 313 y ss. Véase también la obra de H. DAU-LiN: Mutación de la Constitución, ob.cit. Es muy conocido el libro de K. Loewenstein: Teoría de la Constitución, Ariel, Barcelona,1965, quien se ocupa brevemente de la reforma, sobre la mutación pp. 164-170. LOEWENSTEIN ya había traducido al alemán Modern democracies de BRYCE. Contemporáneo de LABAND y amigo de BRYCE es A.V. DiCEY: Introduction to the study of the Law of the Constitution, Mac Millan and Co. Londres, 1961, con introducción de E.C.S. WADE, original de 1885, DICEY define allí las convenciones constitucionales, otro aspecto de la dinámica constitucional.

11 Cfr K.C. Wheare: Las constituciones modernas, ob.cit. P. DE VEGA: ob.cit., epígrafe 3 «Las modificaciones no formales de las Constituciones», p. 177-215. A.V. SÁNCHEZ URRUTIA:» Mutación constitucional y fuerza normativa de la Constitución. Una aproximación al origen del concepto» en $R E D C, \mathrm{n}^{\circ} 58,2000$, pp. 105-135. J. Carpizo: Constitución mexicana. Reforma y mutación, Porrua, México, 2010. G. Rollnert: «La mutación constitucional, entre la interpretación y la jurisdicción constitucional» en $R E D C, \mathrm{n}^{\circ} 101, \mathrm{pp} .125$ 155. Sobre cómo la pasividad del poder de reforma ha provocado la mutación por la jurisprudencia J. GARCíA RocA: «El intérprete supremo de la Constitución abierta y la función bilateral de los Estatutos: o la 
La revisión como actividad de estudio. Al hablar de la reforma atenderé a la «revisión» de los textos constitucionales: la labor de someter sus normas a examen para corregirlas o enmendarlas. Una actividad cognitiva antes que volitiva, de estudio e informe, previa a la reforma y encaminada a la ordenación y actualización de los textos constitucionales para consolidarlos. Consolidar el Derecho es convertir un conjunto sistemático de normas en definitivas o estables, afianzando lo que existe, y volviendo a juntar las piezas deterioradas o disgregadas hasta que vuelvan a quedar firmes. Una actividad de puesta al día, típica de cualquier Derecho codificado. Pueden disociase «revisión» y «reforma» o andar cogidas de la mano y, a menudo, preceder la primera a la segunda un buen tiempo hasta que las circunstancias políticas permitan la reforma. No creo sea cierto que hablar sobre la reforma de una constitución devalué su autoridad o eficacia normativa, pues no ocurre así con el resto del Derecho codificado, ni que desvalorice los pactos constitucionales. Tales cosas sólo pueden ocurrir cuando la correspondencia entre normalidad y normatividad constitucionales se ha ya resquebrajado, o son serios y manifiestos los defectos que se advierten, o los compromisos constitucionales iniciales se han deteriorado hasta difuminarse. Ese es el momento adecuado para la reforma.

La reforma es derivada y limitada. Identidad constitucional. Como tercera delimitación, toda verdadera reforma supone la permanencia del núcleo esencial de la constitución modificada: el respeto de una identidad constitucional ${ }^{12}$. No llega a ser un poder constituyente originario, sino que su legitimidad democrática, el alcance de sus modificaciones, el procedimiento y las mayorías para su aprobación derivan de una constitución previa que intenta mantenerse, y que precisamente por eso se reforma, asumiendo un carácter derivado. Una reforma no es un atentado a la constitución sino una actualización de la misma. La rígida estabilidad y la flexible dinamicidad de las normas constitucionales, su capacidad de impulso y adaptación, deben ir juntas, pues una constitución es una estructura a través de la cual fluye la realidad ${ }^{13}$. Toda verdadera reforma constitucional es limitada. Así Bryce recordaba que en la Constitución de los Estados Unidos era en la que resultaba más difícil introducir cambios, y no había sido nunca revisada en su totalidad sino sólo «enmendada» ${ }^{14}$. También Carl Schmitt explicaba que la reforma es una facultad extraordinaria, pero limitada, pues debe garantizar «la identidad y

insoportable levedad del poder de reforma constitucional» en Revista Catalana de Dret Public, $\mathrm{n}^{\circ}$ 43, 2011, pp. 87-120.

12 El artículo 9 de la Constitución de la República Checa de 1992 establece una cláusula de identidad constitucional «Constitution may be suplemented or amended only by Constitutional Acts» (apartado $1^{\circ}$ ) que es también una cláusula de «eternidad» (Ewigkeitsklausel): "The substantive requisites of the democratic, law-abiding State may not be amended» (apartado $2^{\circ}$ ).

13 Vid P. LuCas verdú: Curso de Derecho Político, volumen II, Tecnos, Madrid, 1974, Capítulo X «Constitución y dinámica constitucional», y Capítulo XI «Teoría jurídica de los cambios de la Constitución».

14 J. BRYCE: Constituciones flexibles y constituciones rígidas, ob.cit., p. 84. 
continuidad de la Constitución considerada como un todo» ${ }^{15}$. La facultad de reformar una Constitución tiene límites.

Reforma y revisión total. No obstante, algunas reformas constitucionales muy intensas y con objetos múltiples pueden calificarse como «revisión total» y así lo hacen algunos textos constitucionales (v.gr. el artículo 168.1 CE), por impreciso que resulte el deslinde ${ }^{16}$. Se emplea la palabra revisión entonces no como se ha usado antes sino como una reforma plena o radical desde una segunda acepción del término. Si se afectan las decisiones políticas básicas de una constitución, la calificación es más sencilla, pero, a menudo, se trata sólo de una diferencia de grado y puede no ser fácil advertir el salto cualitativo. La revisión total es una variante de reforma, pero puede hasta llegar a erigirse en un nuevo poder constituyente $^{17}$.

Rigidez y defensa de la constitución. La rigidez se introdujo en las constituciones del período liberal sobre todo como un instrumento de defensa de la constitución ${ }^{18}$. El constitucionalismo democrático ha recibido esta herencia. Pero a la vez Sieyès defendía el principio de absoluta libertad de cambio de las constituciones por parte del pueblo titular del poder constituyente ${ }^{19}$. Recordemos que el artículo 1 del título VII de la Constitución francesa de 1791 decía: «la asamblea nacional constituyente declara que la nación tiene el derecho imprescriptible de cambiar su propia constitución». Prever y ordenar el cambio es una forma racional de preservar la estabilidad de una constitución ${ }^{20}$, los nuevos valores y necesidades sociales introducen transformaciones y las constituciones deben acomodarse a ellas ${ }^{21}$.

15 C. Schmitt: Teoría de la Constitución, Revista de Derecho Privado, Madrid, 1934, traducción de F. AYALA, pp. 119-120, f 11 «Conceptos derivados del de Constitución».

16 Así p.ej. J. PÉrez Royo: ob.cit, capítulo VIII, habla de la «revisión» de la constitución como «revisión total», siguiendo el mismo entendimiento que se emplea en el artículo 168.1 CE y que es usado en otros países. La expresión se usará en ambos sentidos en este trabajo: a) la aprobación de cambios profundos de las constituciones, y b) el estudio de la actualización y consolidación de las mismas.

17 La Constitución suiza (artículos 192 y 193) permite su reforma «en todo momento, en todo o en parte», la «reforma total» incluso puede ser aprobada tras iniciativa popular. Se exige que la reforma total sea aprobada por el pueblo. Asimismo, la Constitución argentina (artículo 30) afirma que puede reformarse «en el todo o en cualquiera de sus partes». Pero excluye de la iniciativa legislativa popular la reforma constitucional (artículo 39). También la excluye la Constitución española (artículo 166 CE).

18 G. de Vergottini: Derecho Constitucional Comparado, Espasa-Calpe, Madrid, 1983, p. 167, Sección IV «Variaciones de la Constitución», trad. e intr. de P. LUCAS VERdú, hay ediciones italianas posteriores.

19 Cfr E. SIEYÉs: ¿Qué es el tercer estado?, Aguilar, Barcelona, 1973, original de 1788; Escritos y discursos de la Revolución, CEPC, Madrid, 2007, ed. y trad. de R. MAíz. P. DE VEGA: ob.cit., p. 27, recuerda la polémica entre SIEYÈs y LA FAYETTE sobre si el poder constituyente era una obra del genio francés o una tradición constitucional norteamericana, y terciaba diciendo que fue una «exigencia de la práxis» y una «necesidad histórica».

20 J. BRYCE dirá: «the men who sat in the Convention of 1787 were not sanguine enough...to suppose that their work could stand unaltered for all times to come» en The American Commonwealth, vol. I, The MacMillan Company, Londres, 1889, $3^{\mathrm{a}}$ ed, p. 364,

21 Vid L. SÁNChez Agesta: «Orden constitucional y cambio» en Homenaje a Eleuterio Elorduy S.J., Universidad de Deusto, 1978, pp.329-337. 
La reforma como poder constituido. Podría colegirse de esta idea la pretensión de que los órganos que reformen la constitución y sus modalidades deban ser los mismos que los que la aprobaron, esto es, el poder constituyente ${ }^{22}$. Pero esta tesis no tiene sentido. Un poder de reforma, por definición derivado, puede impetrar la legitimidad democrática del texto originario y seguir para actualizarlo un procedimiento allí previsto y fundado en requisitos de más fácil consecución, pues la labor principal ya está hecha. El poder de reforma es un poder constituido, derivado, y regulado en el texto constitucional según argumentó Pedro de Vega ${ }^{23}$.

¿Reforma o cláusula de vigencia limitada? Recordemos el debate clásico entre Jefferson y Madison que concluyó sosteniendo con realismo que las constituciones no debían tener un período de vigencia limitada. Pese a que la primera solución al dilema fue «sacrificar el constitucionalismo a la democracia, de manera que la fuerza vinculante de la Constitución no se extendiese a quienes no pudieran consentirla» ${ }^{24}$ : un período de una veintena de años. El espacio de sendas generaciones para calibrar los cambios en situaciones y las subsiguientes diferencias ${ }^{25}$. Pero la contrapartida a no incluir una cláusula de caducidad en las constituciones fue la previsión de un procedimiento de reforma que permitiera actualizarlas. El origen de la reforma está en ser una alternativa a la vigencia ilimitada de las constituciones, y no sólo es una manera de defenderla frente a cambios demasiado tempranos o profundos.

Limites a la reforma. ¿Vincular a las generaciones futuras? Esta facilitación de la reforma, así como su legitimidad derivada, la voluntad de su revisión periódica, y su carácter de poder constituido, presuponen la posibilidad de límites a la reforma impuestos por el soberano que creó la constitución ${ }^{26}$. Pueden no preverse, pero las constituciones suelen introducirlos. Cualquier poder constituyente tiende a querer mantener su obra para las generaciones futuras con cierto optimismo histórico. Puede incluso sentir la tentación de cerrar la puerta al enemigo del pacto constituyente, y concebir el procedimiento y los límites a la reforma desde esta perspectiva reactiva ${ }^{27}$. Pero la pretensión de «blindar» las

22 Véase G. DE Vergottini: ob.cit., p. 167, quien alude a J. Barthelemy.

23 P. de VEGA: ob.cit., p. 235. El poder de revisión — concluye- no es un auténtico y soberano poder constituyente.

24 Puede leerse la exposición del debate de Francisco RUBIO: «Rigidez y apertura en la Constitución» en La reforma de la Constitución: ¿hacia un nuevo pacto constituyente?, Centro de Estudios Políticos y Constitucionales, Madrid, 2009, la cita en p. 22.

25 S. Muñoz Machado: Vieja y nueva Constitución, Crítica, Barcelona, 2016, asevera que Th. JefFerson fijó el tiempo ideal de una constitución en diecinueve años y explico su aserto con meticulosas razones biológicas y económicas (p. 7), esta tendencia ha desaparecido, si bien nos seguimos preguntando si una generación puede imponer sus criterios a las generaciones futuras, véase el capítulo II de esa obra.

26 Entre otros muchos, la síntesis de G. DE VERGoTTINI: ob.cit., pp. 171-173, quien menciona numerosas constituciones.

27 Vid. E. Tierno Galván: «Especificaciones para un Derecho Constitucional de la transición» en VVAA: Liberalismo y socialismo: problemas de la transición, Tucar, Madrid, 1975, pp.109-122, quien se refería al 
constituciones frente al cambio - $-\mathrm{y}$ en general cualesquiera normas - es tan ingenua como la de «poner puertas al campo», según nos enseñaron primero Cervantes y luego Octavio Paz. Cuando el río sube de caudal, antes o después, se lleva el puente. Jefferson sostenía que «ninguna sociedad puede hacer una constitución perpetua» ${ }^{28}$.

Limites explícitos y sustanciales. En este contexto, es notorio que caben límites explícitos y sustanciales, verdaderas cláusulas de intangibilidad o eternidad eternity clauses - sobre aspectos identitarios de una comunidad política. Son frecuentemente consecuencia de procesos revolucionarios, conflictos bélicos, o de transiciones que afectan a la forma de gobierno o de Estado, o de consultas al pueblo en referendos, o de ingredientes ligados a la constitución histórica de un país. Pueden referirse a aspectos como son la monarquía o la república, el federalismo, la dignidad humana y la inviolabilidad de los derechos, la laicidad o la separación Iglesia-Estado ${ }^{29}$. No siempre son muestras de aguda inteligencia, porque nada es eterno y cuando una sociedad cambia sus valores las normas de cualquier rango cambian. Por el contrario, mientras los valores constitucionales son compartidos

optimismo revolucionario de todo poder constituyente que trata de condicionar los desarrollos futuros; y advertía de que existe una conexión acrítica entre las ideas de constitución y de perfección: «la constitución escrita expresa la perfección»

28 Th. Jefferson: Escritos politicos. Declaración de independencia. Autobiografía. Epistolario, Tecnos, Madrid, 2014, p. 421. Entre las primeras cartas, la escrita a J. MADison en París el 6 de septiembre de 1789 (p. 418 y ss) sobre «la cuestión de si una generación humana tiene derecho a vincular a otra». Se defendía que «esta obligación no puede transmitirse», en esencia, "porque los vivientes tienen la tierra en usufructo»; nadie puede por derecho natural vincular las tierras que ocupe ni a las personas que sucederán en su ocupación, y lo que es cierto para un miembro de una sociedad lo es también para todos colectivamente: «la tierra pertenece a cada una de estas generaciones durante su transcurso...por derecho propio». «Como la mayoría de la generación contratante seguirá existiendo treinta y cuatro años, y entonces una nueva mayoría entrará en posesión, la primera puede extender su compromiso hasta el cumplimiento de dicho plazo y no más». Ese término era el que se estimaba entonces le restaba de vida a una persona mayor de edad a los veintiuno.

En su contestación a ésta y a otra carta, J. MADISON dirá que no veía «la doctrina compatible en todos los respectos con el curso de los asuntos de la humanidad», y se preguntaba si «no engendraría tan periódica revisión facciones perniciosas» y «si no es posible la idea del asentamiento tácito sin subvertir por ello los fundamentos de la sociedad civil»; limitar la validez de las leyes a la vida calculada de una nación «no resulta en todas las ocasiones una exigencia de la teoría y en otras no es posible acomodarlas a la práctica»; admitía que le proporcionaría «singular placer» ver proclamado el principio, pero «éste es un placer del que tengo pocas esperanzas de gozar» (República y libertad, Centro de Estudios Políticos y Constitucionales, Madrid, 2005, «Carta a Tomas Jefferson sobre las generaciones de 4 de febrero de $1791 »$, pp. 101 y ss).

29 Artículo 1 LFB: la dignidad humana es intangible y los derechos inviolables; según el artículo 79, tampoco pueden modificarse la organización de la Federación en los Länder y su participación en la legislación, así como los principios recogidos en el artículo 20 referidos al orden constitucional federal, democrático y social. Artículo 139 Constitución italiana: no podrá ser objeto de revisión la forma republicana. De manera muy razonable, la Constitución suiza (artículos 193.4 y 194.2) establece que ni la reforma total ni la parcial pueden violar las normas imperativas de Derecho Internacional. La Constitución turca (artículo 174) prohíbe reformar una serie de leyes constitucionales que llevaron a implantar el laicismo de la República, frente al viejo sultanato, en tiempos de Kemal Atatürk,; y se discute si tienen una jerarquía supraconstitucional. 
no son precisas intangibilidades. Otras veces, los límites materiales están engastados en la constitución histórica de un país como ocurre en muchos estados pluriculturales o plurinacionales con el federalismo. Por estas razones no me muestro partidario de fijar límites materiales expresos.

Limites temporales. Reformas precipitadas. También pueden existir límites temporales, ya sea porque no haya transcurrido suficiente tiempo desde la revisión anterior, o para prevenirse frente a un reformador acelerado y precipitado $^{30}$. Extremada urgencia en la tramitación y reforma de una norma con autoridad suprema y por definición estable es una contradicción en sustancia ${ }^{31}$. Así lo ilustra la precipitada reforma del artículo 135 CE en 2011 para adoptar un freno constitucional al endeudamiento siguiendo las exigencias del Derecho de la Unión. Al hacerse a la carrera, por el procedimiento de urgencia y en lectura única, varias cuestiones esenciales se olvidaron: el control del déficit de las Comunidades Autónomas y la configuración de autoridad fiscal independiente; y la legitimidad democrática de la reforma resultó además controvertida pese a emanar de la «constitución» europea ${ }^{32}$. Una reforma constitucional no puede precipitarse sin merma de su eficiencia, legitimidad democrática y virtualidad integradora. Es un guiso a fuego lento siguiendo un procedimiento sosegado, participativo y deliberativo, porque el resultado debe ser inclusivo ${ }^{33}$.

Procedimientos deliberativos pero accesibles. En efecto, toda buena reforma reclama unas cautelas en los procesos de cambio entre el Derecho nuevo y el viejo $^{34}$. No obstante, la Constitución francesa de 1791, Título VI, artículos 1 a 6, fijaba un complejo sistema de aprobación por sucesivas legislaturas, hasta tres, que imagino hubiera hecho imposible la reforma ante la acusada rigidez del procedimiento, y, no contenta con esto, impedía la reforma en la legislatura sucesiva y la siguiente. Igualmente, la Constitución de Cádiz de 1812 establecía cautelas sobre «el modo de proceder para hacer variaciones en ellas» y mandaba

30 Significativamente, la Constitución francesa (artículo 89) prohíbe iniciar la reforma «mientras sufra menoscabo la integridad del territorio». La Constitución belga (artículo 196) prohíbe iniciar la revisión o continuarla en tiempos de guerra o cuando las Cámaras no puedan reunirse libremente en el territorio federal; así como modificar los poderes del Rey durante una regencia (artículo 197). También la española (artículo 169 CE) impide iniciar la reforma en tiempo de guerra o de vigencia de algún estado de emergencia.

31 Curiosamente, el artículo 116 de la Constitución de Chile afirma que «será aplicable a los proyectos de reforma constitucional el sistema de urgencias».

32 Cfr J. García Roca y M.A. MARTínez LAGO: Estabilidad presupuestaria y consagración del freno constitucional al endeudamiento, Thomson-Reuters-Aranzadi, Madrid, 2013.

33 E. ÁLVAREZ CONDE admite que una reforma constitucional no permite atajar todos los problemas, pero recuerda que coadyuva a la creación de una «cultura de la negociación» y del acuerdo. E. ÄLVAREZ CONDE (dir.): Reflexiones y propuestas sobre la reforma de la Constitución española, Comares, Granada, 2017, pró$\operatorname{logo}$ p. X.

34 H. Nogueira: «La reforma constitucional en el constitucionalismo latinoamericano vigente» en Boletín Mexicano de Derecho Comparado, $\mathrm{n}^{\circ} 219,2010$, sistematiza los procedimientos de reforma de la región y también los límites. 
que «Hasta pasados ocho años después de hallarse puesta en práctica la Constitución en todas sus partes, no se podrá proponer alteración, adición o reforma en ninguno de sus artículos» (artículo 375), sentando una especie de largo período de prueba, al tiempo que fijaba también un mecanismo de aprobación por legislaturas sucesivas. Es evidente que estos primeros modelos liberales fueron excesivos en su prudencia y cautela. El constitucionalismo democrático debe seguir ahora pautas más accesibles para desdramatizar la reforma y hacerla un instrumento plenamente normalizado y no pesado y difícil de manejar ${ }^{35}$; así lo sugerimos un grupo de expertos en el informe Pautas para una reforma constitucional ${ }^{36}$.

Emergencias y situaciones bélicas. Igualmente se decantan límites negativos o prohibiciones cuando no se dan las circunstancias idóneas que permiten un debate constitucional distanciado, un momento constitucional. Así ocurre en tiempo de guerra o de vigencia de algunos de los estados de emergencia (artículo 169 CE). En tiempos de turbulencias no deben hacerse mudanzas constitucionales. Pero a veces será inevitable hacerlo cuando acabe una guerra, un conflicto bélico, o un emergencia, y el Derecho deba asentar la paz y resolver litigios pendientes ${ }^{37}$.

¿Límites tácitos o implícitos? Discutimos, desde hace décadas, si existen límites tácitos o implícitos, ya que ningún ordenamiento constitucional puede mantener su continuidad si se rebasan las instituciones y principios de la parte esencial de su constitución. Si bien este corolario dista de ser evidente, como muestra el clásico debate entre Mortati y Biscarett ${ }^{38}$. Ciertamente, ninguna constitución puede abrir la puerta y consentir una revocación de sus principios y decisiones políticas básicas y albergar la pretensión de mantener su legitimidad de partida. El problema reside en quién determina e identifica esos límites tácitos y cuál es su alcance $y$, paralelamente, la intensidad de las transformaciones ${ }^{39}$. La dificultad

35 J. PÉREz ROYO: La reforma de la Constitución, ob.cit., p. 31 cita a CoRWIN quien advertía que la maquinaria de enmienda de una Constitución es «unwieldly and cumbrous»: pesada y difícil de manejar. No es extraño pues que algunos partidos se resistan a usarla.

36 J. García Roca (ed.): Pautas para reforma constitucional. Un informe para el debate, Thomson-Reuters-Aranzadi, Madrid, 2014, epígrafe 10 «El procedimiento de reforma constitucional» con ponencia de A. García Martínez.

37 Sobre v.gr. los acuerdos de paz en Colombia, puede verse M. CEPEDA: «The peace process and the Constitution: Constitution making as peace making» en https://iacl-aidc-blog.org/.

38 Cfr P. BISCARETTI DI RUFFíA: «Sui limiti della revisione costituzionale» en Annali del Seminario Giuridico Università di Catania, vol. II, Napoles, 1949, pp. 12 y ss, quien rechazaba la existencia de límites absolutos e implícitos; y C. Mortati: «Concetto, limiti, procedura della revisione costituzionale» en Scritti di Diritto Costituzionale in memoria di Luigi Rossi, Giuffré, Milán, 1952, p 391 y ss, quien creía que la limitación es connatural a la reforma misma. LuCAS Verdú: Curso de Derecho Político, ob.cit., p. 644, terciaba en el debate y reprochaba a BisCARETTI separar las prescripciones relativas a los límites del núcleo central de la Constitución.

39 Un ejemplo del decantamiento de un límite implícito a la reforma constitucional, el artículo 10.1 CE sobre la dignidad humana y la inviolabilidad de los derechos, es J. Jiménez CAMPo: «Algunos problemas de interpretación en torno al título $\mathrm{X}$ de la constitución» en $R D P, \mathrm{n}^{\circ} 7,1980$, pp. 81-101. Pero limita poco. 
es semejante a cuando se afronta la aventurada labor de identificar los enemigos de una sociedad abierta ${ }^{40}$.

\section{LA REFORMA COMO DECISIÓN POLÍTICA Y SU CONFORMACIÓN JURÍDICA.}

Una discrecional decisión política. Potestas y auctoritas. La reforma constitucional es una decisión política, muy libre y discrecional, la más discrecional posible. No siempre es el fruto de la razón o de las opiniones de la academia o de una comisión de expertos ni un precipitado lógico del buen Derecho. Si bien las labores parlamentarias puedan verse asistidas por comisiones asesoras de expertos; así se hizo p.ej. en la II República en España donde la tradicional Comisión General de Codificación se disolvió y se creó la Comisión Jurídica Asesora que redactó un anteproyecto constitucional, aunque luego fueran las Cortes las que hicieron su propio proyecto parlamentario ${ }^{41}$. Pero la reforma es una expresión de potestas, no de racionalidad y auctoritas, sino de oportunidad política. Una muestra del monismo de la ley más que de su dualismo siguiendo la conocida terminología de Zagrebelsky, un poder de decisión antes que la razón ${ }^{42}$, auctoritas non veritas facit legem sostuvo Hobbes. No tiene por qué ser una reflexión racional, aunque a menudo así ocurra. Otra cosa es que sea más probable que una reforma resulte constitucionalmente adecuada y exitosa en su impacto, si viene fundada en razones objetivas y se corresponde con las recomendaciones de los tribunales y/o el acuerdo de la mayoría de la doctrina científica, todos ellos enriquecidos por el distanciamiento y las lecciones de conflictos y experiencias jurídicas.

Tiempos de reforma y labores de comunicación. Mas el tiempo de la reforma, el momento y el ritmo de las transformaciones, la intensidad de las modificaciones, y, sobre todo, la imprescindible pedagogía de los representantes para explicarla a la opinión pública son decisiones fundadas en criterios de oportunidad política, y no actividades jurídicas regladas o deducibles de normas previas. Sin políticos y partidos políticos a la altura de un momento constituyente, la reforma es imposible. Los cambios constitucionales se derivan de la capacidad de generar amplios acuerdos entre partidos. Una reforma constitucional exige representación, participación, transparencia y, en particular, una política de comunicación. Explicar adecuadamente las reformas constitucionales a las opiniones públicas nacionales, dirigir y medir el tempo de ejecución de la pieza son labores mucho más difíciles que las estrictamente técnico-jurídicas en la confección de la partitura.

40 Puede leerse K. Popper: La sociedad abierta y sus enemigos, Paidos, Barcelona, 1982, el original en inglés es de 1945, fecha que explica muchos de sus contenidos.

41 Puede consultarse L. Jiménez De Asúa: Proceso bistórico de la Constitución de la República española, Reus, Madrid, 1932, p 1 y ss.

42 Cfr G. Zagrebelsky: Il giudice delle leggi artifice del diritto, Editoriale Scientifica, Nápoles, 2007. 
Reforma y función de integración política. Esto es así porque una constitución cumple una función de integración ciudadana, de pacto fundador de una comunidad política, mediante la asociación de individuos y a menudo de entes territoriales $^{43}$. La reforma renueva estas dimensiones de asociación, integración y legitimidad. No es una norma cualquiera ya que se encuentra en el vértice del ordenamiento. Si todo parlamento es un gran dispensador de legitimidad democrática, el procedimiento de reforma aún más, pero sólo si se realiza con las debidas garantías. Si la constitución no sale reforzada en su legitimidad tras la reforma, la misma es fallida. El mero cambio normativo sin estas notas sirve de poco.

Un poder sometido en parte al Derecho. El poder de reforma no es, sin embargo, simplemente res facti non iuris: un poder al margen del Derecho. Viene sometido a algunas limitaciones constitucionales, -temporales, materiales o de procedimiento_- más o menos densas según los diferentes ordenamientos. Pero sigue siendo un poder esencialmente político, ubicado en un lugar intermedio entre el excepcional poder constituyente, soberano, y los cotidianos poderes constituidos, los órganos constitucionales supremos encargados de la dirección política de todos los días. La frecuencia de la reforma debería, por consiguiente, ser también intermedia entre la actividad de aquél poder excepcional, un poder de los días festivos, y los poderes ordinarios y cotidianos, en especial, el legislativo.

Patologías. El uso autoritario de la reforma constitucional en varios países europeos para abrogar decisiones garantistas y fundadas en Derecho de tribunales constitucionales es una evidencia reprobable de su caracterización como una muy libre decisión política. Igualmente, aquellas reformas constitucionales pensadas por una mayoría para avasallar los derechos de ciertas minorías molestas, ya sean políticas, étnicas o religiosas ${ }^{44}$. O las reformas constitucionales que en algún país iberoamericano vacían los mandatos, reservas y prohibiciones constitucionales para habilitar al legislador ordinario o al gobierno y tomar decisiones que les eran ajenas, sustituyendo a otros poderes y devaluando el propio sistema de garantías. Sin embargo, un buen Derecho Constitucional reclama ambas cosas, potestad y autoridad persuasiva, mientras todas estas son patologías, ejemplos de meras expresiones de poder desnudo de razones. Los hombres se gobiernan por leyes en la cultura del constitucionalismo y no por otros hombres, aunque sean mayoría.

¿Fraude constitucional o rodeo a la constitución? Algunas de estas patologías pueden llegar a constituir verdaderos abusos o fraudes constitucionales. Pero

43 B. Alaez: ob.cit., Capítulo II, párrafo 2, pp. 68-72, insiste en que la Constitución es la ordenación jurídica del proceso de integración: una constitución no sólo es norma sino realidad integradora. También lo hace F. Moderne: Reviser la Constitution. Analyse comparative d'un concept indeterminé, Dalloz, Paris, 2006, p. 15, acudiendo a Heller y a SMEND.

44 La Constitución noruega de 1814, aún vigente y bastantes veces modificada, quedó desactualizada en algunas de sus prescripciones, la más famosa llevó a la eliminación en 1851 y 1897 del «párrafo judío» en el artículo 2, ya que, tras adoptarse la religión evangélico-luterana como oficial del Estado, se prohibía el ingreso de judíos al reino, de jesuitas y órdenes monacales. 
ambas categorías son difíciles de precisar en sus contornos jurídicos. No puede predicarse el abuso de todos los derechos fundamentales sino sólo de algunos y en ciertos $\operatorname{casos}^{45}$, y la desviación de poder en el ejercicio de una potestad difícilmente podría aplicarse al poder de reforma ante situaciones de arbitrariedad, pues sus fines son libres. Igualmente, la idea de fraude a la constitución fue acuñada en otros contextos diversos, con cierta confusión, y no se admite unánimemente ${ }^{46}$. Todo fraude a la ley reclama tres cosas: una norma de cobertura, otra segunda cuyos mandatos pretenden eludirse, y la consecución de un resultado prohibido por el ordenamiento como consecuencia de la norma de cobertura que rodea esa segunda norma. En la teoría del Derecho, el rodeo a la ley es un ilícito atípico ${ }^{47}$. ¿Podríamos aplicar esta técnica en un control de constitucionalidad?

¿Reformar el procedimiento de reforma? En España — y también en otros paísesse ha discutido si podría reformarse el procedimiento de reforma agravado (artículo $168 \mathrm{CE}$ ), para simplificar sus requisitos, siguiendo el procedimiento ordinario (artículo $167 \mathrm{CE}$ ) que es de más fácil tramitación. Una simplificación de los requisitos facilitaría las reformas. Mi posición es que, en la medida que el propio procedimiento de reforma no viene protegido por el artículo 168, esta actuación no puede estimarse necesariamente inconstitucional sin necesidad de agregar mayores razones, puesto que no existe una prohibición expresa ${ }^{48}$. Un argumento simple pero consistente: no está prohibido en las normas constitucionales y las prohibiciones deben ser reglas expresas y no juicios lógicos inferidos de principios. La competencia del poder de reforma podría no venir limitada por la dualidad de rigideces. Pero admito que la posibilidad de la modificación mediante un procedimiento de reforma en doble grado resultaría paradójica y previsiblemente aminoraría la legitimidad política de la reforma ante la opinión pública. Es asimismo una posibilidad rechazada en sede teórica por diversos expertos con razones de peso ${ }^{49}$. Conviene

45 Véase J. García Roca: «Abuso de los derechos fundamentales y defensa de la democracia (art. 17 CEDH)» en J. García Roca y P. SAntolaya: La Europa de los derechos. El Convenio Europeo de Derechos Humanos, ob.cit., pp. 727-756.

46 G. Liet-Veaux: «El fraude a la Constitución. Ensayo de un análisis jurídico de las recientes revoluciones políticas: Italia, Alemania, Francia» en Revista Peruana de Derecho Público, 2005, nº 10, pp. 11-41, traducción de S. Díaz Ricci, original en francés de 1942. Pero el concepto no se construye con precisión y se entiende como «una distorsión del sentido institucional», «sin violar las formalidades externas».

47 Cfr M. Atienza y J. Ruiz Manero: Ilícitos atípicos (sobre el abuso del derecho, el fraude a la ley y la desviación de poder), Trotta, Madrid, 2000.

48 También piensa así S. Ragone: I Controlli giurisdizionali sulle revisioni costituzionali : profili teorici e comparativi, Bolonia University Press, 2011, existe traducción al español El control judicial de la reforma constitucional: aspectos teóricos y comparativos, Porrúa, México, 2012.

49 P. DE VEGA: ob.cit., capítulo 4 «Los límites ... a la reforma constitucional», distinguía entre límites absolutos y relativos y concluía que sólo los segundos pueden ser eliminados con procedimientos especiales (p. 243). Sostenía, con su habitual brillantez, que «la tesis de la reforma en doble grado resulta...tan ingeniosa como insostenible», «una simple manifestación de audacia y un artilugio formalista» (p. 265-267). Una vez admitida la distinción entre los poderes constituyentes y de reforma, el segundo no puede reformar las normas en que se le reconoce su propia competencia. «Los límites explícitos son jurídicamente insuperables» salvo mediante una acción revolucionaria. Sin embargo, admitía — puede que en contradicción- que la que creía superioridad 
admitir que un procedimiento regular y adecuado a las circunstancias es condición necesaria, aunque no suficiente, para que una reforma sea eficiente y comúnmente aceptada.

¿Una decisión parlamentaria o popular? Rigidez y flexibilidad. ¿La reforma es una decisión política de qué sujeto? Normalmente, el poder de reforma se traduce en una mayoría parlamentaria cualificada. Una fracción temporal de un órgano parlamentario en una o dos cámaras, constituida por dos tercios o tres quintos de los diputados y senadores o cualquier otra mayoría análoga. La idea de rigidez constitucional, según se expuso por Bryce, se contrapone a la de flexibilidad y supone una reforma agravada en el procedimiento frente a la ley, así como la autoridad suprema de la constitución ${ }^{50}$. Viene a dejar atrás la flexibilidad de muchos documentos constitucionales, típica de buena parte del siglo XIX, que podían ser modificables por las leyes como ocurría con el Estatuto Albertino en Italia.

La coincidencia entre representantes y representados. Esta decisión parlamentaria, debatida por los representantes tras la iniciativa de diversos sujetos, puede responder a los deseos e intereses de una mayoría social importante, el pueblo que los parlamentarios representan, y venir luego ratificada - o no- en un referéndum para cerciorarse de esa correspondencia. Puede incluso haber sido propuesta con antelación en una campaña electoral exitosa de un partido y haber sido objeto de aprobación, previa y directamente, por el pueblo. Pero este circuito democrático representativo puede operar en sentido contrario y la mayoría parlamentaria construir artificialmente una voluntad presunta de los representados, que es aún inexistente y no se sabe si responde a sus deseos. Conviene subrayar las dificultades de toda mayoría para vislumbrar con antelación suficiente y sin riesgo de equivocarse la opinión del pueblo cuando se le convoca en un referéndum para la ratificación de un proyecto de reforma aprobado por las Cámaras. Así ha ocurrido en Italia con la llamada «reforma Renzzi» que fue rechazada en referendo el 4 de diciembre de $2016^{51}$, pronto se dijo que «los padres del no» fueron numerosos y

formal, una mayor jerarquía, de las normas amparadas por el artículo 168 sí podía ser suprimida (p. 153, p. 256). A mi entender, no caben dos rangos diversos de normas igualmente constitucionales, de acuerdo con el principio de unidad sistemática, ni diferencias en jerarquía constitucional dentro de un mismo texto; y las mayorías parlamentarias más amplias y sucesivas previstas en el artículo 168 CE no alteran esta conclusión lógica.

50 Véanse los matices que hace A. PACE: «La natural rigidez de las Constituciones escritas» en A. PaCe y J. VArela: La rigidez de las Constituciones escritas, CEC, Madrid, 1995, pp. 19-80. Del mismo autor, entre otros trabajos, Potere costituente, rigiditá costituzionale, autovinculi legislativi, CEDAM, Padua, 1997; y «L'instaurazione di una nuova Costituzione. Profili di teoría costituzionale» en Quaderni Costituzionale, $\mathrm{n}^{\circ} 1$, 1997, p. 7-51, donde defiende que la distinción entre constitución material y formal es inadmisible en una constitución rígida (p.29).

51 E. Rossi: Una Costituzione migliore? Contenuti e limiti della reforma costituzionale, Pisa University Press, 2016, se plantea un doble interrogante: si puede hacerse una revisión de una constitución en ausencia de un verdadero momento constituyente, es decir, sin unas condiciones sociales e históricas adecuadas, y si un poder constituido de reforma puede hacer una reforma de este calado en vez de ejercerse el poder constituyente (p. 223). El primer interrogante es un prius esencial, el segundo muestra la dificultad de deslinde entre revisión total y nuevo poder constituyente. 
mal avenidos. No toda reforma aprobada en el parlamento será ratificada en referéndum, produciéndose la doble integración de voluntades de un acto complejo, fruto del acuerdo de dos o más sujetos: una o dos cámaras y el pueblo en referendo.

¿Referéndum? El referéndum es un instrumento emocional, que se presta a pasiones antes que a razones y, al tiempo, demanda las simplificaciones que exige toda pregunta clara y concisa. Es, por ambas razones, escasamente idóneo para resolver cuestiones muy técnicas y complejas, a diferencia del parlamentarismo y la representación que son el corazón de la democracia moderna. Una decisión y un compromiso parlamentario adoptado a lo largo de años no es cosa equivalente en su complejidad y profundidad a la votación de un día. Las experiencias del Brexit, de la independencia de Escocia y del fallido Tratado constitucional de la Unión acreditan cuanto digo y aconsejan ser prudentes ${ }^{52}$. Muchos referendos adoptan decisiones con escasa participación y pequeñas mayorías - lo que les hace escasamente representativos - y con confusión, desinformación o falsas expectativas respecto de los argumentos para decidir. Sobre todo, generan serias dificultades — si no directamente imposibilidades- en la posterior ejecución de las decisiones, pues las concretas consecuencias de la abstracta pregunta referendaria no suelen explicitarse. Por otro lado, a veces dividen y fracturan las sociedades de manera antagónica, pues las decisiones quedan en las manos de una minoría insuficiente. Finalmente, los polos de agrupamiento de los ciudadanos frente a este mecanismo de participación directa pueden llegar a ser muy diversos, heterogéneos e incluso contradictorios. La misma participación ciudadana - su engagement o compromiso como dicen los anglosajones- en un referéndum no puede darse por supuesta, y rara vez suele ser mayor que en elecciones, lo que contribuye a rebajar su legitimidad democrática. Recordemos las sabias tesis de Benjamín Constant sobre la libertad de los antiguos y la de los modernos cuando advertía que muchos ciudadanos no desean ser muy activos en su participación y compromisos y prefieren ser repre$\operatorname{sentados}^{53}$. La participación en las redes sociales podría estar cambiando este aserto a ojos de muchos. Incluso en comisiones de la House of Commons se habla de digital democracy y de open parliament, y de fortalecer el compromiso y la transparencia ${ }^{54}$. Daño no hará. Pero me pregunto cuántos millones de personas participan en esas actividades comprometidas, y si son tantos como en elecciones, y advierto que una cosa no puede sustituir a la otra sino complementarla con realismo, o estaremos dando un gran poder a unos pocos activistas en su participación, generosos con su tiempo, en detrimento de muchos

52 Puede leerse J. Tonnos: De Escocia a Cataluña. Referéndum y reforma constitucional, Iustel, Madrid, 2015.

53 B. Constant. Sobre el espíritu de conquista. Sobre la libertad en los antiguos y en los modernos, $2^{\text {a }}$ ed. Tecnos, Madrid, 2002, discurso pronunciado en 1819.

54 Open Up' Digital Democracy Commission's Report en http://www.digitaldemocracy.parliament.uk. 
representados. En definitiva, el referéndum no debería convertirse en un milagroso bálsamo ante la desafección de los ciudadanos y, en especial, de las más jóvenes respecto de las instituciones representativas, sin necesidad de mayores reflexiones, tal y como bastantes tienden actualmente a creer ${ }^{55}$. En particular, las innovaciones constitucionales requieren amplios compromisos y acuerdos, un ejercicio de democracia «consociativa» (consociationalism), pero sólo en algunos casos es imprescindible el referéndum, ambas cosas no deben identificarse sin mayores razones según más adelante se razonará.

¿Con qué procedimiento? Rigidez y autoridad suprema. La reforma es normalmente una función del legislativo, pero asegurarse de su autoridad suprema reclama introducir requisitos formales agravados ${ }^{56}$, si bien existentes múltiples variantes de procedimiento. Estos requisitos agravados permiten distinguir la reforma de las leyes ordinarias y en ellos se plasma la rigidez constitucional al servicio de la autoridad suprema de las constituciones ${ }^{57}$. El sometimiento a procedimientos más exigentes que los seguidos para legislar ${ }^{58}$ resguarda asimismo el texto constitucional de «veleidades de mayorías coyunturales» y de "propuestas sin suficiente respaldo» 59 . Madison ya nos advirtió que toda mayoría tiene intereses poderosos o pasiones momentáneas, y debemos prevenirnos frente a mayorías estrechas que intenten alterar las reglas del juego. Entre estos requisitos, la aprobación con diversas mayorías cualificadas — dos tercios, tres quintos, tres cuartos—-, a diferencia de las leyes ordinarias que suelen aprobarse por mayoría simple ${ }^{60}$.

55 Puede leerse S. Tienney: Constitutional referéndums. The theory and practice of republican democracy, Oxford University Press, 2012, quien defiende la emergencia o el resurgimiento del referéndum como instrumento de gobierno desde las teorías republicana y deliberativa, y como requisito de la reforma constitucional. Otra razón — a su juicio_ - sería la creciente desafección de los ciudadanos hacia la democracia representativa y la disminución de militancia en los partidos.

56 Es clásico J. Bryce: Constituciones flexibles..., ob.cit. p. 78.

57 Cfr J. BrycE: Constituciones flexibles..., ob.cit. Véanse los matices que formula A. PACE: «La natural rigidez de las Constituciones escritas» en A. PACE y J. VArela: La rigidez de las Constituciones escritas, CEC, Madrid, 1995, pp. 19-80, para el cual la rigidez caracteriza a todas las Constituciones escritas y es una condición natural. Las normas que prevén un procedimiento especial de revisión no constituyen el fundamento de la rigidez constitucional sino su confirmación, e incluso provocan un debilitamiento de la misma. La distinción es cuantitativa y relativa. Así el Estatuto Albertino se pensó como inmodificable y sólo en un segundo momento devino flexible. Ambos autores abren el debate sobre el valor normativo de las Constituciones del XIX. En un sentido análogo la obra de M. MANDEL: The unbearable flexibility of the Statuto Albertino, CLUEB, Bolonia, 2006, que adjunta un ensayo de M. RINALDI.

58 J. PÉrez Royo: ob.cit., p. 20, recuerda que fue en las Constituciones de los Estados norteamericanos en el período 1776-1787 cuando se fue imponiendo la idea de la diferencia de procedimiento entre el poder de reforma y el poder legislativo ordinario.

59 P. Lucas Murillo de la Cueva: ob.cit, p. XVI.

60 El artículo 79.2 de la LFB demanda dos tercios de los miembros del Bundestag y la misma mayoría de los votos del Bundesrat. También pide dos terceras partes de ambas Cámaras el artículo 5 de la Constitución de Estados Unidos. Igualmente, el procedimiento agravado del artículo 168 CE que se contenta con tres quintos de cada Cámara en el procedimiento ordinario. Asimismo, la Constitución de Austria exige dos terceras partes de la Asamblea Nacional antes de aprobarse por la Asamblea federal. En cambio, mayoría absoluta de los componentes de cada Cámara pide la Constitución italiana (artículo 138), pero en dos votaciones sucesivas. La Constitución belga (artículo 195) de 1994 mantiene la tradición decimonónica de la disolución y la 
Un procedimiento parlamentario específico. Los Reglamentos parlamentarios pueden prever un procedimiento específico para la aprobación de la reforma, según resulta aconsejable, o simplemente remitir al procedimiento legislativo ordinario, en todo ${ }^{61} \mathrm{o}$ en parte como acontece en España (véanse los artículos 146 y 147 del Reglamento del Congreso de los Diputados). Me parece que una reforma constitucional es cuestión de suficiente entidad como para que existan unas previsiones reglamentarias sobre su tramitación adecuadas a la naturaleza de la decisión: v.gr. comisiones parlamentarias de estudio, comisiones jurídicas asesoras, audiencias ciudadanas y de expertos, participación de las minorías, debate de totalidad, varias lecturas, o incluso técnicas digitales de open parliament... Claro está que todo ello no tiene por qué estar necesariamente previsto en el Reglamento. Sobre todo, es imprescindible un suficiente sosiego en la tramitación parlamentaria que permita alcanzar compromisos a través de la deliberación. En la reforma se advierte bien que el parlamentarismo es discusión, participación y publicidad. La reforma puede aprobarse por parlamentos monocamerales o bicamerales, $\mathrm{o}$, más raramente, a través de la reunión de las dos cámaras en una asamblea o convención constituyente. Todo ello puede concluir o no en una disolución del legislativo, reclamando el juicio definitivo de los electores en unas elecciones generales y la aprobación sucesiva de la reforma por dos legislaturas. O incluso reservar al pueblo la decisión final en referéndum. O pedir la aprobación por una mayoría — simple o cualificada - de los Estados en las federaciones o confederaciones, inicialmente ${ }^{62}$ o para su reforma ${ }^{63}$.

¿Quéprocedimiento es conveniente? Ya he razonado que no tiene sentido que una reforma parcial y derivada, un ajuste, se someta a los mismos requisitos que la aprobación de la constitución de cuya legitimidad trae origen ni siquiera a otros

aprobación por dos parlamentos sucesivos para la revisión, y reclama dos tercios de los votos. En Argentina, la Constitución (artículo 30) afirma que la necesidad de la reforma deberá ser declarada por al menos dos terceras partes de los miembros del Congreso, pero no se efectuará sino por una Convención convocada a tal efecto. La Constitución de Chile (artículo 116) exige la aprobación de la reforma por tres quintas partes de los diputados y senadores, y dos terceras partes si afecta a unos contenidos más protegidos. En Perú, el artículo 206 de la Constitución reclama la aprobación por mayoría absoluta, pero si se aprueba por dos tercios de los congresistas en dos legislaturas sucesivas se omite el referéndum.

61 La propia Constitución suiza (artículo 192.2) establece que mientras la Constitución o la ley en que se fundamenta no lo disponga de otra manera, la reforma ser llevará a cabo por el procedimiento legislativo. En Chile, la Constitución (artículo 117) determina que la Ley orgánica constitucional del Congreso regulará, en todo lo demás que no se prevé allí, la tramitación de los proyectos de reforma y los vetos presidenciales.

62 El artículo 7 de la Constitución de EEUU establecía que la ratificación por las convenciones de nueve Estados bastaría para que entrase en vigor. El artículo 144 Ley Fundamental de Bonn demandaba la sanción por dos terceras partes de las asambleas legislativas de los Länder.

63 La Constitución de EEUU determina (artículo 5) la ratificación por las legislaturas de las tres cuartas partes de los Estados separadamente o por medio de convenciones. La Constitución suiza establece (artículo 195) que la reforma total o parcial entrará en vigor una vez que haya sido aprobada por el pueblo y por los cantones, se entiende que por mayoría simple. Dos casos de antiguas confederaciones de estados. También la Constitución de México (artículo 135) exige que la reforma se apruebe por la mayoría de las legislaturas de los estados. 
semejantes en cuanto igualmente gravosos. Si pretendemos normalizar la revisión permanente de las constituciones, - como ocurre con la actualización de cualquier Derecho codificado y en este trabajo se defiende-, la reforma debería atribuirse al parlamento y contentarse con su aprobación por una mayoría cualificada que asegure del compromiso parlamentario tras un procedimiento especial tramitado con suficientes garantías de transparencia y participación.

De nuevo sobre el referéndum. Si existe duda sobre si la reforma parcial es realmente una revisión que afecta a las decisiones fundamentales, entonces la participación directa del pueblo, su consulta mediante referendo, es razonable. Si la reforma es de calado, es precisa una base decisional amplia, «una base más ancha y firme» decía James Bryce ${ }^{64}$. Pero recordemos que el poder de reforma es un poder constituido, y el referéndum no debe, por tanto, considerarse indefectible en muchos casos desde el punto de vista teórico. Pero la pregunta acerca de si la reforma constitucional es idónea para su aprobación en referendo no tiene una fácil respuesta en la realidad de las cosas. Dependerá mucho de la cultura política de cada país y de la complejidad y el tecnicismo de la modificación, pero no creo sea insoslayable ${ }^{65}$. En el libro «Pautas para una reforma constitucional» sugeríamos que el referendo sea obligatorio solo en cuestiones esenciales que afecten directamente a la esencia del Título Preliminar de la Constitución española ${ }^{66}$, esto es, a las decisiones políticas básicas.

La activación del referéndum por las minorías. No obstante, es de prever que minorías excluidas del compromiso sobre el pacto reformador soliciten la convocatoria de un referéndum, si está en sus manos hacerlo porque resulte facultativo (p.ej. artículo 167.3 CE, artículo 44.2 Constitución de Austria). El referendo acaba siendo entonces una cláusula de seguridad, una salvaguardia en manos de las pequeñas minorías si sienten que no forman parte del consenso; y adquiere entonces una naturaleza opositora, si bien puede ser asimismo una instrumento de la mayoría en otras ocasiones ${ }^{67}$.

64 J. BRyCE: Constituciones flexibles..., ob.cit., p. 83.

65 No demanda un referéndum la Ley Fundamental de Bonn. Sí lo hace el artículo 138 de la Constitución italiana si lo solicita una quinta parte de sus miembros de una Cámara, quinientas mil firmas o cinco asambleas regionales, pero puede evitarse si se aprobó en una segunda votación por dos tercios de cada Cámara. El referéndum es obligatorio en el procedimiento agravado del artículo 168 CE y potestativo en el procedimiento ordinario del artículo $167 \mathrm{CE}$, si lo pide una décima parte de los miembros de cualquier Cámara. La Constitución francesa (artículo 89) exige la aprobación definitiva en referéndum, pero puede eludirse si el Presidente convoca al Parlamento en Congreso y lo aprueba por mayoría de tres quintos. En Austria, la Constitución (artículo 44.2) reclama referéndum para toda enmienda de conjunto o parcial, pero para la segunda sólo cuando lo solicite un tercio de los miembros de una Cámara. En Chile, la Constitución (artículos 117 y 119) prevé un «plebiscito» para que la ciudadanía se pronuncie si se produce un desacuerdo entre las Cámaras y las observaciones del Presidente. La Constitución peruana (artículo 206) exige la ratificación de la reforma en referéndum, pero puede omitirse si se aprobó por dos tercios de los congresistas en dos legislaturas sucesivas, y se añade que el Presidente no puede vetarla u observarla.

66 J. García Roca (editor): Pautas para una reforma constitucional..., ob.cit., capítulo 10.

67 R. Romboli señala el papel opositor del referéndum, más que de aprobación, es una confirmación de una elección realizada por el parlamento. El pueblo interviene como instancia de freno o confirmación 
Facilitar los procedimientos. Bryce sostenía, al reflexionar con su habitual agudeza sobre los procedimientos, que «la tendencia de los últimos años se ha inclinado hacia más fáciles y rápidos que los empleados durante la primera mitad del siglo XIX», y añadía «en Alemania, los juristas y publicistas están dispuestos ahora a reducir al mínimo la diferencia entre los cambios constitucionales y los estatutos ordinarios» ${ }^{68}$. La tendencia creo debe seguir siendo la misma: métodos sencillos y rápidos, reducir la diferencia entre reforma constitucional y leyes ordinarias, sin dejar de asegurarse de que su superioridad formal redunde en trámites agravados.

¿Cuál es el límite? ¿Cuáles son entonces los requisitos agravados mínimos del procedimiento de reforma? Las soluciones nacionales son variadas y no existe una respuesta universal. Me parece por eso más importante seguir una perspectiva material antes que procedimental. La elaboración de la reforma debe satisfacer los valores que la propia reforma pretende, en particular alcanzar una mayor legitimidad democrática e integración política, en vez de obsesionarse con la prontitud en su aprobación. Participación de las minorías, transacción de la mayoría y deliberación suficiente son rasgos esenciales para asegurarse de los resultados.

Ocassio y justificatio. ¿Cuál es la ocasión y la justificación de una reforma? ¿Cuándo es oportuna? Pedro de Vega sostuvo con brillantez que en «toda situación límite no cabe otro dilema que el de falsear la Constitución o reformarla», lo que equivale a indicar que «la necesidad jurídica...determina su conveniencia política» ${ }^{69}$. Pero me temo que no sea así muchas veces y no estoy seguro de que podamos seguir contemplando esta cuestión desde la razón teórica y el idealismo antes que desde la razón práctica. La reforma no depende del Derecho. Debemos ver esta cuestión con un acusado realismo. La reforma de la constitución es un «asunto que no concierne directamente al constitucionalista» nos dijo sabiamente James Bryce ${ }^{70}$. Esta misma posición defendimos un grupo de expertos al elaborar el informe «Pautas para una reforma constitucional»: la reforma de la constitución es una decisión política ${ }^{71}$. No obstante, el constitucionalista y en general cualquier jurista de Estado no pueden desentenderse del análisis de los defectos de una constitución ${ }^{72}$ y de las pautas para su revisión, aunque su reflexión tenga sólo un valor limitado. Sirve de poco, porque la reforma es una decisión política y depende de factores de oportunidad difícilmente sistematizables y en

sucesiva. Pero de este papel y uso esporádico, «cuando hay disenso hay referéndum», parece haberse pasado últimamente a «cuando hay reforma, hay referéndum» («Il referéndum costituzionale nell'experienza republicana e nelle prospettive di reforma dell'art. 138 Cost.» en Scritti per G. GROTANELLI DE'SANTI: Poteri, garanzie e diritti a sessanta anni dalla Costituzione, Giuffré, 2207, pp. 573-619).

68 J. BRYCE: Constituciones flexibles..., ob.cit., p. 85.

69 P. DE VEga: ob.cit., p. 93.

70 Prólogo de P. Lucas Verdú a J. Bryce: Constituciones flexibles..., ob.cit., p. XXXI, citando Constitutions. Reprint of the Edition de 1905, reditado en 1980, p 95.

71 J. García Roca (editor): Pautas para una reforma constitucional..., ob.cit. p. 20.

72 Es una referencia N. Alcalá Zamora: Los defectos de la Constitución de 1931, Civitas, 1981, original de 1936. 
manos de los partidos políticos. Se advierte bien la modesta dimensión del Derecho Constitucional como Derecho del hecho político ${ }^{73}$ o, en otras palabras, la forma del poder $^{74}$. La reforma no es la consecuencia predecible de una argumentación racional ni de la autoridad de unos principios. No obstante, parte del rol del Derecho Constitucional es orientar la labor del poder y por eso tiene sentido que intentemos reconstruir unos criterios lógicos. Con frecuencia, la razón antes o después se impone, pero me temo que no siempre.

¿Constituciones rígidas y flexibles o mejor Constituciones nuevas y viejas? Bryce sostuvo que las constituciones rígidas eran más modernas que las flexibles, una fase más avanzada del constitucionalismo ${ }^{75}$. El aserto es hoy indiscutible, porque apenas quedan constituciones flexibles además del Reino Unido. Andorra, cuyo caso analizó en los años veinte Fernando de los Ríos, dejó de serlo en $1993^{76}$. Pero conviene dar un paso más. Las constituciones rígidas que se renuevan y actualizan periódicamente son constituciones nuevas o modernas, realmente pertenecientes a su tiempo, frente a aquellas que no lo hacen. La Constitución de los Estados Unidos es un importante símbolo en su país y en el constitucionalismo mundial, pero es una constitución vieja, ya que no aborda con normas suficientemente densas muchos de los problemas actuales v.gr. el derecho al matrimonio que ha debido revisarse judicialmente nada menos que desde la cláusula de proceso debido, muchos nuevos derechos no reconocidos, o el decisivo comercio entre los Estados, cuestión esencial en el federalismo y donde la Corte Suprema se ha visto obligada a efectuar innumerables exégesis de la cláusula de comercio casi imposibles de ordenar. No reformar la constitución deja en manos de los tribunales decir cuál es la constitución ${ }^{77}$. Estas interpretaciones judiciales «mutativas» de las disposiciones constitucionales devalúan la certeza del parámetro del control de constitucionalidad de las leyes; y, sobre todo, producen una seria merma del principio democrático y del compromiso parlamentario permanente como valor republicano y esencia del constitucionalismo. No parece la opción mejor para una constitución democrática $\mathrm{y}$, aunque a veces resulte inevitable, la mutación judicial no debe considerarse como una verdadera alternativa a la reforma constitucional, porque la democracia representativa y la soberanía popular se resienten; tampoco lo es claro está la manipulación de las normas constitucionales por el gobierno y el parlamento mediante exégesis forzadas ${ }^{78}$.

73 G. DE VERGOTTINI: ob.cit., p. 9

74 F. Rubio: La forma del poder (Estudios sobre la Constitución), Madrid, CEC, 1993.

75 J. BRyCE: Constituciones flexibles..., ob.cit, p. 64

76 F. DE los Ríos URruti: Vida e instituciones del pueblo de Andorra. Una supervivencia señorial, Revista de Archivos Bibliotecas y Museos, Madrid, 1920.

77 J. PÉrez Royo: ob.cit., p. 29, llega a decir que la introducción del control de constitucionalidad de las leyes hace que la reforma constitucional pierda gran parte de su sentido. Las consecuencias de esta afirmación, no por exagerada menos inteligente, son tremendas.

78 S. MuÑoz Machado: Vieja y nueva Constitución, ob.cit., p. 10 realiza algunas reflexiones sobre los cambios constitucionales y advierte que empeñarse en cerrar la Constitución a toda modificación, suele 
La renovación de los compromisos constitucionales: constituciones nuevas y viejas. En efecto, sin renovar de tiempo en tiempo los compromisos sobre las direcciones políticas de Estado, el parlamentarismo se devalúa y adquiere problemas de funcionamiento. Sin revisiones periódicas, la idea de la eficacia de una constitución normativa, desprovista de un periodo de vigencia o caducidad, es imposible. Ninguna norma legal dura eternamente. Sin reformas, la legitimidad democrática de la constitución como pacto fundador mengua sensiblemente. Precisamente por eso, el inmovilismo, el mero legalismo desprovisto de consideraciones de legitimidad, no es una actitud propia de un constitucionalismo democrático. Concluiré que la división entre constituciones rígidas y flexibles, una vez casi desaparecidas las segundas, me parece que pierde hoy importancia respecto de la verdadera distinción entre constituciones nuevas o modernas, aquellas que se revisan y actualizan periódicamente, y constituciones viejas. Las nuevas tienden a ser dinámicas y más democráticas, y las viejas, estáticas y más liberales o elitistas y pueden devenir obsoletas.

¿Modificar las leyes o reformar la constitución? La tentación más sencilla y frecuente para muchos gobernantes es modificar las leyes y mantener inalterada la constitución. Pero no son cosas equivalentes ni bienes sustitutivos. Todo problema complejo suele tener una solución sencilla, sólo que equivocada. La agenda política debe advertir esta paradoja. Hay cosas que pueden actualizarse en las leyes. Pero reenviar las transformaciones constitucionales más inaplazables, soslayando la reforma, a modificaciones legales mediante artificios de ingeniera constitucional, o a sesudos y densos informes administrativos fruto de comisiones de reforma integradas por funcionarios no acaba siendo eficaz ${ }^{79}$. Esta actitud simplista no resuelve los problemas, sino que los dilata y merma el respeto a la cultura del Estado de Derecho, desdeñando la voluntad de vivir en constitución. Cuando la casa común tiene problemas de arquitectura no suele funcionar contentarse con pintar las paredes. En España, ensayamos en 1994 una reforma encubierta del Senado, al crear una Comisión General de las Comunidades Autónomas en el Reglamento de la Cámara, un pequeño Senado dentro del Senado, pero este artificio de ingeniería no funcionó y la reforma de la segunda cámara sigue siendo en 2016 una asignatura pendiente en nuestra arquitectura constitucional. A veces estas tentativas fallidas sirven al menos para ratificar la necesidad de reformas constitucionales.

¿Cuál es la materia de la reforma? Un problema habitual reside en saber cómo «separar las leyes fundamentales de las demás, para lo cual es generalmente necesario tener una experiencia considerable en el arte de gobernar y en los asuntos

conducir a que sus reglas sean paulatinamente sustituidas por otras en la práctica por simple vía de hecho. Ese es uno de los riesgos principales de las constituciones viejas.

79 Informe de la Comisión para la Reforma de las Administraciones Públicas (Informe CORA), 2016, www. transparencia.gobierno.es/transparencia. 
políticos» ${ }^{80}$. ¿Cuál es la materia de la reforma constitucional y cuál la de la ley? En Europa, el debate acerca del freno constitucional al endeudamiento para consolidar la estabilidad presupuestaria, una política de la Unión plasmada en sus propias normas, llevó en Alemania y Polonia a una seria discusión — no así en España- sobre si era un contenido constitucional y tenía tal supremacía material, tal y como se concluyó finalmente, pero en otros países la prohibición de endeudamiento excesivo continúa teniendo rango legal ${ }^{81}$. Esta alternativa muestra la indeterminación del problema. Las normas constitucionales son transversales y se diferencian esencialmente por su mayor jerarquía y no siempre por sus contenidos. Los ejemplos podrían ser muchos, el caso de México, paladín de las reformas muy frecuentes y un excelente laboratorio al respecto, nos permitirá ahondar en el problema más adelante.

¿Cuál es el contenido de la constitución? Normas constitucionales reglamentistas. Este interrogante en buena medida se reconduce al debate clásico sobre el contenido de la constitución y las ideas formal y material a cuyos términos reenvío. Salvo las cuestiones esenciales respecto de los derechos fundamentales y la división de poderes, existe una zona de incerteza en muchos extremos sobre la materia constitucional. Dónde ubicamos las fuentes del Derecho, la nacionalidad y la extranjería, la regulación detallada de la organización constitucional y administrativa o de los órganos auxiliares, o las normas electorales y parlamentarias, o las normas sobre consolidación presupuestaria, etc. El deslinde entre el contenido constitucional y el de las principales leyes de desarrollo constitucional (reglamentos parlamentarios, leyes del gobierno, leyes del poder judicial, leyes de tribunales constitucionales...) se basa en criterios de grado acerca de lo que es esencial o fundamental. Es conveniente evitar la redacción de normas constitucionales reglamentistas, de detalle en exceso, tan rígidas como para dificultar su modificación. Pero es una opción política del poder constituyente, quien puede querer proteger ciertos contenidos constitucionalizándolos o, por el contrario, dejarlos en manos de las leyes para favorecer modificaciones. Los sistemas electorales pueden ser un buen ejemplo de una materia que no se debe constitucionalizar en su totalidad para permitir el progreso e innovaciones. Pero la decisión puede ser distinta en un momento de transición a la democracia. Mas cierta restricción al constitucionalizar materias es harto razonable de acuerdo con la idea de supremacía constitucional.

Reformas accesorias o enmiendas independientes. La reforma normalmente será accesoria del texto principal de la constitución, como toda enmienda al articulado $^{82}$, ya sea de adición o de modificación o de supresión, pero también pueden

80 J. Bryce: Constituciones flexibles..., ob.cit, p. 64.

81 Cfr J. García Roca y M.A. Martínez LAGO: Estabilidad presupuestaria y consagración del freno constitucional al endeudamiento, ob.cit.

$82 \mathrm{El}$ artículo 79 LFB prescribe que «sólo puede ser reformada por una ley que expresamente modifique o complete su texto». 
introducirse cuestiones nuevas ${ }^{83}$, no previstas en las constituciones ni siquiera mínimamente, y entonces ese carácter accesorio no existe, aunque quepa reclamar una homogeneidad material o coherencia sistemática respecto del texto de la constitución. Una constitución es un conjunto sistemático de normas desprovisto de contradicciones. La innovación no puede desentenderse de una interpretación de concordancia práctica, deben impedirse las contradicciones y mantenerse la unidad sistemática de una constitución. Así la Constitución de Noruega de 1814 (artículo 112) establece que las enmiendas no pueden contradecir los principios que emanan de la Constitución sino sólo modificar disposiciones específicas «sin alterar el espíritu» de la misma. Recordemos que, en algunos sistemas, caben amendments o adiciones al texto constitucional más que verdaderas enmiendas.

La bipertrofia de la reforma. Sobriedad constitucional y rigor normativo. En países como México, donde se han dado cientos de reformas - 642 cambios a través de 225 decretos de reforma hasta 2015-, el contenido de la reforma es una cuestión central $^{84}$. También el abuso de la misma. El legislador ordinario puede tener la tentación de colgar en la constitución cualquier contenido desde meros artículos reglamentistas al verdadero diseño de políticas públicas ${ }^{85}$. Este crecimiento desmesurado no es aconsejable, porque acaba produciendo una hipertrofia o elefantiasis constitucional: un desarrollo excesivo de una norma suprema que, al ser la cabeza de un ordenamiento jurídico, debe recoger sus epígrafes más generales, pero no apoderarse del resto del cuerpo. Bien es verdad que la apertura de una constitución a su reforma frecuente puede ser un factor de estabilidad política, de un lado, y, de otro, que cada país posee su cultura política ${ }^{86}$. Pero las constituciones modernas deben ser sobrias y austeras, y no adornarse en exceso ni entrar en demasiados detalles, tanto para permitir direcciones políticas contrapuestas como para facilitar su aplicación por un conjunto de tribunales y administraciones.

Leyes de desarrollo constitucional. Ante la situación descrita, se comprende bien el Anteproyecto de Ley de Desarrollo Constitucional que han defendido doctrinalmente Héctor Fix Fierro y Diego Valadés ${ }^{87}$, pese a que no parece vaya a ser aprobado. Parece una reacción lógica, frente a continuas reformas durante décadas, con voluntad de recuperar las proporciones adecuadas de una Ley Fundamental. La sensación de vértigo es mayor si se advierte que casi el $67 \%$ de los 642 cambios de un artículo constitucional han sido posteriores a la modernización iniciada en $1982^{88}$. El Anteproyecto pretendía revisar el texto constitucional,

83 La Const. de México (artículo 135) precisa que «la presente Constitución puede ser adicionada o reformada».

84 Los datos son de H. Fix-Fierro y D. Valadés (coord.): Constitución política de los Estados Mexicanos. Texto reordenado y consolidado. Ley de Desarrollo Constitucional Anteproyecto, UNAM-Cámara de Diputados, México, 2016, p. 2.

85 Idem, p. 12.

86 Idem, p. 21.

87 Idem, passim

88 Idem, p. 5 . 
mejorando su redacción y presentación sistemática, sintetizar los preceptos demasiado largos, y trasladar los contenidos reglamentistas a una Ley de Desarrollo Constitucional; y se sugería aprobar ambas cosas simultáneamente. Esta curiosa técnica, con tradición en el pensamiento jurídico mexicano, podría cumplir una función relevante. Las constituciones modernas no pueden ser muy largas ni albergar defectos como los que estos autores describen: deficiente sistemática, errores en la concordancia de los preceptos, terminología variable e inconsistente, disparidad en las regulaciones, artículos reglamentistas... ${ }^{89}$. Descargar la vieja Constitución de 1917 de una larga sedimentación histórica de preceptos podría dar esplendor al texto y facilitar su exégesis. De aprobarse, habría que observar el funcionamiento de esta técnica, poco conocida en Derecho comparado, por si ayuda a regenerar constituciones muy largas y reformadas en exceso, o, por el contrario, se estimara atípica y no generalizable. Puede que acaso sea una medicina circunscrita al desmesurado crecimiento de las normas constitucionales mexicanas.

\section{LOS DEFECTOS DE UNA CONSTITUCIÓN FORMAL.}

Precisión normativa. Bryce decía que los dos méritos distintivos de las constituciones rígidas son la precisión y la estabilidad ${ }^{90}$. La precisión es conveniente por razones análogas a las de cualquier norma jurídica, pero se ven acrecentadas al erigirse las normas constitucionales en parámetro de un control de constitucionalidad. Un fenómeno con una intensidad que el británico no podía sospechar. La justicia constitucional debe tener un serio impacto en la confección de las normas constituciones, tecnificándolas y juridificándolas en vez de proclamarlas como declaraciones políticas. Un lenguaje coloquial en las constituciones puede que no sea ya posible: la simplicidad, la austeridad y el rigor son deseables frente al barroquismo. Las normas constitucionales tienden a ser muy abiertas, un Derecho muy concentrado por su brevedad, generalidad y abstracción. Debe por eso evitarse la vaguedad de las mismas ${ }^{91}$ : la imprevisibilidad e incerteza de sus normas. Por otro lado, un exceso de precisión normativa, que impida desarrollos legales diversos, puede hacer demasiado rígida la constitución. No es sencillo mantener un equilibrio entre ambos polos.

Estabilidad. La estabilidad si es excesiva puede también llegar a ser un inconveniente. Con el fin de impedir un exceso que acabe produciendo la obsolescencia de las normas, las constituciones deberían revisarse cada década: el doble de una legislatura. Con el transcurso del tiempo, se advierten omisiones, imprecisiones,

89 Idem, pp. 8-12.

90 J. BRyCE: Constituciones flexibles..., ob.cit., p. 87.

91 Puede leerse T.A.O. EndicotT: Vagueness in Law, Oxford University Press, 2000. 
defectos, lagunas, nuevos problemas necesitados de regulación, viejos asuntos necesitados de nuevas regulaciones, nuevas aproximaciones culturales y tecnológicas que no conocía la generación anterior o que no compartía.

¿Interpretación originalista? Una constitución debe ser interpretada a la luz de las condiciones de vida actuales y no de las pretéritas. Una interpretación originalista de una constitución es un sinsentido lógico cuando no se prevé una cláusula de caducidad o período de vigencia limitada ${ }^{92}$. Ninguna ley puede ser eterna y menos aún una constitución. ¿Cómo vamos a resolver a la luz del siglo XviII los nuevos problemas del siglo XxI? No es extraño que los tribunales constitucionales hayan seguido muy mayoritariamente una interpretación evolutiva y dinámica. Qué opinión podía tener el constituyente español de 1978 sobre la inmigración y los derechos de los emigrantes en un país habituado desde siglos a lo contrario, o sobre la regulación de las telecomunicaciones, o sobre los derechos de los homosexuales. Es frecuente mencionar en el federalismo estadounidense el ejemplo del petróleo como un nuevo recurso energético, constitutivo de una competencia residual a favor de los Estados, cuyo valor era desconocido al aprobarse la Constitución.

La revisión como juicio previo a la reforma. La constatación de las deficiencias e insuficiencias de cualquier constitución deben llevar a su periódica revisión: al estudio de su aplicación para en su caso actualizarlas. La revisión puede no concluir en la apertura de un procedimiento de reforma, que acaso no se estime necesario o sea aún prematuro o insuficientemente consensuado. Pero es una operación estructural de mantenimiento y acopio de información y reflexión harto aconsejable. Cualesquiera reformas constitucionales de calado son lentas (v.gr. las acaecidas en Suiza, Alemania y Austria), su maduración puede durar lustros o décadas, y las instituciones deben tener los trabajos preparatorios hechos para no improvisar las modificaciones.

Tipos de lagunas y omisiones. Recordaré la enunciación de omisiones en las normas constitucionales que hizo Bryce ${ }^{93} \mathrm{y}$ de la que arrancaré. Primero, el silencio constitucional: asuntos pasados por alto por el constituyente quien se abstuvo de decidir sobre ellos por alguna razón. Frecuentemente, no es lícito pensar que la constitución dejó su solución en manos del legislativo, ya que esto alteraría el equilibrio de la división de poderes entre los poderes constituyente y constitui$\operatorname{dos}^{94}$, y para dar respuestas adecuadas al silencio debería impulsarse la reforma constitucional. Segundo, también verdaderas omisiones, carencias en las regulaciones y asuntos que pasaron inadvertidos en las constituciones; a veces no están claramente fuera del ámbito del poder legislativo y podrían resolverse en todo o en

92 El artículo 146 LFB establecía su pérdida de vigencia cuando se consumase la unidad y libertad de Alemania y entrase en vigor una constitución adoptada por la libre decisión del pueblo alemán. Sobre este precepto puede leerse M. BACigALUPO: «Política y Constitución en la Alemania actual» en $R E P, \mathrm{n}^{\circ} 75,1992$, pp. 271-290.

93 J. Bryce: Constituciones flexibles..., ob.cit., p. 89.

94 Vid J. García Roca: «Del principio de la división de poderes» en REP, nº108, 2000, pp. 41-75. 
parte en las leyes, de forma diferente según cada mayoría parlamentaria, o mediante usos y convenciones, alcanzando cierta elasticidad.

Interpretaciones manipuladoras. En ocasiones esas supuestas omisiones o carencias en las regulaciones no son tales sino realmente manipulaciones de las constituciones por parte de los gobernantes sin acatar el espíritu de sus normas: verdaderas interpretaciones manipuladoras. ¿Tiene sentido parlamentario que el líder del partido más votado en unas elecciones rechace presentar su candidatura y pedir la confianza de la Cámara para su investidura tras su conversación con el Jefe del Estado presuponiendo el rechazo de los parlamentarios? ¿No existen unas normas no escritas de la corrección constitucional que limiten estas conductas? ¿La prohibición legal de iniciativa legislativa gubernamental del Gobierno en funciones no conlleva la del decreto-ley que es una herramienta más poderosa que la mera iniciativa? ¿Pueden llegar a preverse todos estos extremos en las normas constitucionales? El debate en España sobre el alcance de las competencias limitadas del Gobierno en funciones, y por ende de un parlamento sin Gobierno, ilustra que sus funciones se podrían precisar algo más en el muy lacónico artículo 101.2 CE y bastante más en la Ley del Gobierno y en Reglamento del Congreso, aprendiendo de las experiencias adquiridas en más de trescientos días sin investidura de un nuevo Presidente. Pero ni las normas constitucionales ni las reformas pueden prever cualquier cosa, aunque puedan luego llegar a ocurrir en forma de pesadillas. El Derecho escrito no puede solventarlo todo, el respeto de los principios constitucionales es imprescindible.

Interpretaciones judiciales y leyes parásitas. Finalmente, existen asuntos donde el significado dudoso de las normas constitucionales reclama una interpretación, jurisdiccional o legal, «las palabras pueden ensanchar y transformar una constitución» decía Bryce, quien hablaba de «leyes parásitas», refiriéndose a las leyes que viven a costa de las constituciones ${ }^{95}$.

Estabilidad e inmutabilidad: la rigidez como peligro. ¿Hasta dónde debe llegar la estabilidad de las constituciones rígidas? La estabilidad da seguridad a los ciudadanos, pero no puede confundirse con la inmutabilidad: la condición de irreformable de una constitución no es sino un suicidio. «Los experimentos son el alma del progreso», la realidad no es siempre tan estable como parece y en la rigidez existe «un elemento de peligro» nos enseñó Bryce, porque se pierde la elasticidad que en cambio poseen las constituciones flexibles; un puente de hierro - decía - que no se adapta a los nuevos elementos puede venirse abajo de un golpe ${ }^{96}$. Las tempestades populares crecen ante la imposibilidad de realizar modificaciones. No es extraño - afirmaba Bryce- que los descontentos a quienes se ha prohibido cualquier salida legal, porque no puede obtenerse la mayoría legalmente prescrita, encuentren desahogo en una revolución o en una guerra civil. La historia del problema de la esclavitud en EEUU es un buen

95 J. BRyCE: Constituciones flexibles..., ob.cit., p. 91

96 Idem, p. 92-94. 
ejemplo, afirmaba el norirlandés: la constitución no resolvió el problema, treinta años más tarde hubo serias disputas, otros treinta después, una guerra civil $^{97}$. La situación actual en Cataluña, el reiterado incumplimiento de la ley por los gobernantes autonómicos y el impulso hacia la desobediencia civil en torno al llamado "derecho a decidir», es otra muestra de lo que ocurre si se rechaza una mutación de la Constitución en un Estatuto de Autonomía —algo que no es jurídicamente posible - y no se ofrece a cambio una reforma de la Constitución territorial como alternativa ${ }^{98}$, y la votación en referéndum de un texto de reforma de la Constitución o del Estatuto ${ }^{99}$. Cuando se cierra una puerta debe abrirse una ventana y no sólo en el cielo.

La conexión entre una constitución irreformable y la ilegalidad. La ausencia de revisión de una constitución rígida es pues un impulso hacia la ilegalidad y la ruptura, y, con mayor razón, cuando los adversarios o críticos de las constituciones van creciendo en número y no se postula su reforma por la indolencia o la levedad de los gobiernos. La mayoría que se resiste a revisar las constituciones, sin esgrimir razones, no puede merecer el honorable calificativo de conservadora sino el de promotora de revoluciones. Porque las reformas constitucionales se diseñan e impulsan desde el Gobierno y no desde la oposición. Bryce nos lo advirtió: «La constitución rígida está dispuesta para resistir ciertos cambios, pero lo mismo que el puente se viene abajo de un golpe, está amenazada de ruina por las tempestades populares, que se alimentan y crecen de la imposibilidad de realizar modificaciones en determinadas condiciones por medio de enmiendas» ${ }^{100}$. El exceso de rigidez, la condición de irreformable, es un elemento de peligro para la vida de las constituciones.

Constituciones irreformables y compromisos constituyentes. Esta otra patología, la cualidad de irreformable de una constitución, no deriva de la dificultad del procedimiento agravado, de la rigidez formal, sino de la viabilidad de un compromiso constituyente entre fuerzas políticas antagónicas. Éste es el problema central en la reforma de las constituciones y escapa al mundo del Derecho: la capacidad de una mayoría parlamentaria de encontrar aliados para aprobar una reforma constitucional. Sin embargo, el constitucionalista no puede desentenderse de este asunto y, como aprendimos de Triepel, debe saber reflexionar en esta frontera entre política y Derecho público antes de volver al Derecho, pero su papel es modesto, y subalterno o ancilar ${ }^{101}$.

97 Idem, p. 95.

98 Vid P. Pérez Tremps: «¿Qué reforma de la Constitución y quién la reforma?» en www.bez.es.

99 J. García Roca: «La reforma de la Constitución territorial: un buen camino entre secesión e inmovilismo» en Teoría y Derecho, $\mathrm{n}^{\circ}$ 16, 2016, pp. 16-31, monográfico sobre la reforma constitucional y el Estado autonómico.

100 J. BRyCE: Constituciones flexibles..., ob.cit., p. 94.

101 H. Triepel: Derecho Público y política, Civitas, Madrid,1974, con prólogo de J.L. Carro, una reflexión sobre el método aparecida en 1926. 


\section{EL PACTO CONSTITUCIONAL QUE MANTIENE UNA CONSTITUCIÓN ESCRITA: LAS CONDICIONES MATERIALES.}

Constitución formal y condiciones materiales. La estabilidad de una constitución no depende pues de la rigidez del procedimiento sino de la estabilidad de las condiciones que le permitieron cuajar, como pronto comprendió Bryce ${ }^{102}$. No obedece tanto a la validez de sus normas como a «su conexión con la realidad» ${ }^{103}$. En otras palabras, deviene esencial la persistencia en el tiempo del acuerdo entre las fuerzas sociales y económicas que crearon una constitución y luego la impulsan y sostienen. Una constitución pretende mantener unida a una nación ${ }^{104}$. Satisface así una función política primordial, aún más importante que sus esenciales funciones jurídicas como norma jurídica a la cabeza de un ordenamiento y fuente de fuentes. Una buena constitución mantiene la unidad de una nación mediante la asociación de sus ciudadanos y entes territoriales.

Función de integración política: renovar los pactos. Mas esto sólo puede hacerse vertebrando racionalmente la asociación de los miembros de una comunidad, en virtud de transacciones recíprocas entre fuerzas adversarias, y no mediante la imposición de sus normas mediante la coacción, que es algo que, por definición, debe ser excepcional. La reforma prolonga la función constitucional de integración que describió Rudolf Smend ${ }^{105}$; debe cerrar las brechas y renovar los pactos constitucionales. Esta es su función política esencial. La reforma permite adaptar la constitución a la realidad y debe verse no como un obstáculo al cambio sino como una «invitación»y «fuente de consenso» ${ }^{106}$. Pero no todas las fuerzas políticas observan la realidad de la misma manera y a veces es lento que lleguen a compartir los diagnósticos. Entre otras razones, porque la realidad pone a prueba la capacidad de una constitución para adaptarse a los cambios sociales: su misma elasticidad. No faltan quienes creen que las constituciones pueden siempre modelarse y flexibilizarse casi hasta el infinito, lo que ocurre es que a veces se rompen. El «mito» de la constitución, un «respeto decente», es un poderoso factor decía Wheare que «evita o demora el cambio» ${ }^{107}$. También Bryce advirtió que ha sido un hábito de los

102 J. Bryce: Constituciones flexibles..., ob.cit., p. 28.

103 P. Lucas Murillo De La Cueva: ob. cit., p. XV.

104 J. BRyCE: Constituciones flexibles..., ob.cit., p. 95.

105 R. SMEnd: Constitución y Derecho Constitucional, CEC, Madrid, 1985, original de 1928, aunque el concepto de «integración» aparece antes en un trabajo sobre la forma política Die politische Gewalt im Verfassungstaat und das Problem der Staatsform (1925) y luego en Staatsrechtliche Abbandlungen und andere Aufsätze, Dunker\&Humbolt, Berlín, 1955. Sobre los efectos simbólicos de las Constituciones, véase Dieter GRIMM. «Integration by Constitution» en International Journal of Constitutional Law, n 2-3, 2005, pp. 193-208, describe la integración como la condición para la unidad y la acción colectiva, y resalta que se produce en el mundo real no en el normativo, las constituciones no controlan ese proceso. Pero advierte que se somete a las Constituciones a expectativas que van mucho más allá de su función reguladora

106 P. LuCAS Murillo: ob.cit., pp. XXV y XXVII.

107 K.C. WhEARE: ob.cit., p. 83. 
americanos hablar de su Constitución «with an almost supersticious reverence» ${ }^{108}$. Creo que, igualmente, el prestigio de la transición a la democracia en España ha contribuido a sacralizar el texto de 1978 y diferir la inevitable reforma. Desaparecido el pacto entre las fuerzas políticas que desde 1977 vertebraron el compromiso constitucional, la revisión es aconsejable. El problema es que ese pacto aún no existe en 2016.

¿Una constitución en sentido material? La realidad política. En este contexto, la necesaria correspondencia entre constitución formal o documento escrito y pacto constitucional, tiene interés la vieja doctrina italiana de la «Constitución en sentido material» acuñada por Costantino Mortati en 1940, pese a resultar muy polémica $^{109}$. La erudición, densidad y ambigüedad — no sé si calculadas o juvenilesde la elaboración del maestro italiano se hace aún más patente al contraponerla con la sabiduría, sencillez y claridad de la reflexión del británico Bryce. No desdeño el interés de esta tesis clásica, pues la terminología me parece una intuición genial, pero la doctrina no llega a construirse con claridad y suficiencia jurídicas y arroja serias sombras y riesgos y por eso no creo pueda asumirse. Si bien el objeto mismo de esta reflexión, la realidad política que circunda una constitución, no puede soslayarse en una teoría de la revisión y esto es lo que intento mostrar.

Valedores y refractarios. La adopción de la tesis de Mortati se ha visto rechazada y sometida a serios reproches ${ }^{110}$. No obstante, también se ha defendido diciendo que supone una decisiva revalorización del papel que cumple la realidad social, que ya no está «confinada en lo prejurídico», si bien después suele añadirse que permite «la fuerza normativa de la voluntad política» ${ }^{111}$. A mi entender, la primera afirmación puede ser cierta, pero el segundo aserto no puede ser aceptado sin arrojar por la borda el valor normativo de la constitución. Los defensores de la tesis sostienen que las fuerzas políticas capaces de caracterizar un ordenamiento, cumplen un papel en la fijación de los principios y fines fundamentales para la organización de un Estado, y, con frecuencia, no lo hacen a través de modificaciones constitucionales; tienden a no hacer coincidir la supremacía material de los contenidos con la supremacía formal y se contentan con modificaciones en nor-

108 J. BRYCE: The American Commonwealth, ob.cit., p. 368.

109 C. Mortati: La Costituzione in senso materiale, Giuffrè, Milán, 1940, sostenía que es necesario un principio unificador de carácter sustancial frente a exigencias sociales siempre en renovación; no es posible una unidad abstracta del Estado. F. MODERNE: ob.cit., p. 9 a 18, analiza también la revisión de la constitución desde las ideas de constitución formal y material.

110 Vid G. ZaGrebelsky: «Considerazioni sulla fortuna attuale della dottrina della Costituzione in senso materiale» en Studi in onore de Leopoldo Elia, Giuffrè, Milán, 1999, pp. 1773-1806, quien recoge las posiciones de muchos, caracteriza el realismo de MORTATı frente al positivismo formalista y advierte que no volvió prácticamente a emplear la tesis tras el fascismo; y J. JimEnEz CAMPO: «Contra la Constitución material» en Estudios de derecho público en homenaje a Juan José Ruiz-Rico, Tecnos, Madrid, 1997, pp. 42-54. Puede leerse el estudio preliminar de A. Bergareche a C. Mortati: La constitución en sentido material, CEPC, Madrid, 2000, con un epílogo de G. Zagrebelsky.

111 G. DE Vergottini: ob.cit., p. 143, con fundamento en Mortati, Barile, Fioravanti... 
mas de otro tipo; en particular, ocurre así con las fuerzas políticas hegemónicas o dominantes ${ }^{112}$.

Normas materialmente constitucionales fuera de las constituciones. El razonamiento que acabo de sintetizar constituye una adecuada descripción de la realidad constitucional en muchos momentos, pero es sumamente peligroso para la vigencia del Derecho Constitucional. En todos los Estados con constituciones rígidas hay normas materialmente constitucionales, recogidas en usos constitucionales o en textos infraconstitucionales de diverso rango. En España, los acuerdos autonómicos de 1981 y 1992 se consideraron como convenciones constitucionales. La ordenación de las fuentes del Derecho se encuentra en parte en el Título Preliminar del Código Civil de 1974. La reprobación individual de los ministros es un uso parlamentario no previsto ni en la Constitución ni en el Reglamento del Congreso de los Diputados. Hay asimismo normas materialmente constitucionales en el Derecho Europeo.

Normas constitucionales abiertas y mutaciones. Que el Presidente del Congreso pilote la investidura de un Presidente del Gobierno en la fase de consultas, y no sólo el Rey, ha mutado y restringido el sentido de la prerrogativa regia en virtud del expansivo alcance del refrendo traslativo de la responsabilidad política. Son muchos los ejemplos. El agotamiento de las regulaciones en normas constitucionales escritas sólo se produce en presencia de reglas precisas. Las normas muy abiertas y los principios admiten la creación de usos y costumbres en defecto de normas que modulen las mismas. Mas algunas de estas exégesis pueden poner en peligro la normatividad constitucional y ese es el riesgo. Así la experiencia del Gobierno en funciones en España durante trescientos dieciséis días a caballo de la XI y XII Legislatura, ha restringido indebidamente el control parlamentario hasta otorgarle un carácter caprichoso o arbitrario, dejando su ejecución en las manos del controlado, el propio Gobierno ${ }^{113}$.

La constitución material no puede derogar la constitución formal. El pacto constitucional. Pero el que acabo de exponer no es el verdadero riesgo que plantea la tesis de Mortati. Admitiré que la constitución en sentido material o, con un sentido más adecuado, el pacto constitucional pueden ser la fuente de validez y de eficacia del documento constitucional; ambas ideas, con sus diferencias, suponen la existencia de una dirección política de Estado que impulsa la creación de una constitución y alienta su mantenimiento y eficacia. Si la constitución en sentido material desaparece y no es sucedida por otra sobrevenida que acepte la herencia, la revisión puede devenir imposible, y la constitución puede situarse en riesgo o incluso al borde de su desaparición. El mantenimiento de una constitución formal depende de unas condiciones materiales en la realidad política. Ya Bryce

112 Ibidem

113 Vid J. García Roca: «¿Puede rechazar el control parlamentario un Gobierno en funciones?» en E. ARANDA (coord.): Lecciones constitucionales de 314 días con el Gobierno en funciones, Tirant lo Blanch, de próxima publicación. 
sostenía lo mismo que Mortati en este extremo y la coincidencia no es casual. Podemos llamar este fenómeno con distintas terminologías, y desde luego impedir algunos de los excesos, pero es manifiesto que una constitución normativa no se mantiene a sí misma, como visualiza la imagen del Baron von Münchausen empeñado en tirarse del pelo de la cabeza hacia arriba para salir de la ciénaga en la que había caído, tal y como pretende la respuesta del positivismo clásico, que suele responder a la cuestión con cierta retórica formalista. ¿Quién crea la constitución que está en el vértice del ordenamiento? Sin un conjunto de fuerzas políticas y sociales que mantengan la validez y eficacia del pacto constitucional mediante sucesivas actualizaciones y compromisos, la vida de una constitución no puede ser larga. Mortati creía que esta realidad, la constitución material, era un «hecho normativo». Pero mantener la autonomía jurídica de esa constitución material respecto de la formal no me parece posible.

La interacción entre constituciones y naciones. Desde una perspectiva complementaria, Bryce hablaba de «la influencia de las constituciones en la mentalidad de las naciones ${ }^{114}$. Esta proposición me parece que puede recorrerse al revés con mayor interés: hay una influencia de la mentalidad de las naciones en la reforma de las constituciones. Algunos Estados tienen una cultura más ligada que otros al respeto de ideas constitucionales como son Rule of Law, Rechtsstaat o pouvoir constituant con sus matices y diferencias. Son países con tradiciones democráticas e ilustradas que hicieron una revolución liberal y burguesa y no desdeñan el valor del Derecho en democracia. La mayor parte de los Estados tienen una constitución, pero en buen número de ellos es menos apreciada decía Wheare ${ }^{115}$. En casi todo el siglo XIX y $\mathrm{XX}$, la constitución ha sido poco más que una placa de yeso en las plazas de los pueblos de España y ya casi se nos había olvidado. Bryce añadía que «tres cosas parecen necesitarse: espíritu legal, afición y talento para la ley»; un cierto pensamiento conservador y una lozanía intelectual encaminados a una actividad que rechaza la petrificación; sólo donde estas cualidades se mezclan adecuadamente —afirmaba — se puede desarrollar una constitución y reformarla ${ }^{116}$.

Un momento constitucional: el pacto con el enemigo. Reformar una constitución reclama ciertas condiciones cívicas e históricas: el compromiso con ciertos principios republicanos y democráticos. Muchos países no están en condiciones de aprobar una constitución ni de reformarla. En las constituciones monárquicas el pacto constituyente surgía entre el soberano y el pueblo a través de una asamblea. Con el paso de la soberanía al pueblo y la universalidad del sufragio, la idea de pacto se transforma. Toda reforma constitucional verdaderamente pactada dispensa una gran legitimidad democrática a las instituciones, pero debe fundarse en transacciones recíprocas de los partidos políticos hasta alcanzar compromisos.

114 J. BRyCE: Constituciones flexibles..., ob.cit., p. 51-52.

115 K.C. WhEARE: ob.cit., p. 10

116 J. BrycE: Constituciones flexibles..., ob.cit., p. 52. 
Se ha dicho que toda reforma de una constitución entraña un pacto político con el enemigo ${ }^{117} \mathrm{o}$, cuando menos, con el adversario.

El dinamismo del pacto federal. Del mismo modo, el foedus federal, el pacto entre unos entes territoriales que se alían en común provecho, debe ser permanentemente actualizado. Es preciso mantener el equilibrio entre fuerzas centrífugas y centrípetas que entraña cualquier proceso de descentralización, tanto si se trata de una vieja confederación de Estados soberanos que avanza hacia el federalismo unitario como de un viejo Estado unitario que se descentraliza, en ambos casos, es menester renovar el pacto de tiempo en tiempo. No es desde hace muchas décadas un problema de soberanía como algunos nacionalistas en España tienden a creer, asumiendo como ideario un concepto de otra época. Las constituciones federales y cuasi federales deben revisarse frecuentemente para mantener el equilibrio en competencias y finanzas entre autogobierno e integración. El abandono de la vieja soberanía de los Estados en el federalismo o su relativización en la doctrina europea y americana tras un extenuante debate se sustituye por la constante renovación del pacto de descentralización en un proceso permanente. La reforma de una constitución federal tiene rasgos específicos y suele reclamar una mayor frecuencia, porque un proceso federal es dinámico: los acuerdos en lenguas, financiación y competencias no pueden mantenerse décadas sin renovarse.

El exponente de la constitución. Por último, la defensa de la constitución y de su función unitaria no justifican que un único partido, aunque sea el hegemónico, la minoría mayoritaria, se cierre «a toda concordia con la pretensión de defender el verdadero exponente de la Constitución» decía Bryce ${ }^{118}$. En el mismo sentido, se manifestó Rubio Llorente ${ }^{119}$. Quien rechaza renovar el pacto constitucional no es un defensor de la constitución. Las constituciones no se defienden guardándolas dentro de un sagrario sino actualizándolas, y para ello es menester advertir una acusada elasticidad de sus normas y abrigar una flexible capacidad de pacto. Nadie puede arrogarse el monopolio de su exposición ni convertirse en modelo de virtudes constitucionales. Una constitución no es de un partido sino de una nación.

\section{LA TENSIÓN ENTRE ESTABILIDAD Y DINÁMICA CONSTITUCIONALES. CONSTITUCIONES VIEJAS Y NUEVAS.}

Cambio social y transformación constitucional. Wheare nos decía que cualquier constitución es un producto de su tiempo, y se preguntaba qué ocurre si el tiempo cambia y se producen desarmonías entre una constitución y la realidad social ${ }^{120}$.

117 Vid P. PÉrez Tremps: ob.cit.

118 J. BRyCE: Constituciones flexibles..., ob.cit., p. 96.

119 F. Rubio: «Proceso constituyente, clamor popular y otros desvaríos» en www.ahorasemanal.es.

120 K.C.WHEARE: ob.cit., pp. 76-83. 
¿Cambiarán las constituciones? Añadía que las fuerzas que provocan el cambio o se resisten al mismo pueden concentrarse en transformar la sociedad, desinteresándose de la reforma o, por el contrario, impulsar la misma. Los tiempos de guerra, las crisis económicas — sostenía - han sido fuerzas centralizadoras y han reforzado a los ejecutivos. No menos impacto ha tenido la evolución del sistema de partidos y por ende del sistema electoral en el desarrollo. O aquello que los ciudadanos piensan sobre la constitución. Pero los factores sociales que transforman las constituciones no siempre conducen a una reforma ${ }^{121}$. Corremos, por tanto, el riesgo de que cambio social y sucesión normativa constituyan una línea asíntota y visualicemos la imagen de una línea que se acerca continuamente a una curva, pero sin llegar a encontrarla.

¿Cuándo cambian realmente las constituciones? Wheare se preguntaba pues qué factores originan verdaderamente las reformas de las constituciones, pero sus respuestas no superan el umbral de la indeterminación. Si bien nos advierte que los países que se han tomado en serio sus constituciones y su vigencia efectiva han utilizado ampliamente su procedimiento de reforma ${ }^{122}$. También nos recuerda que un Gobierno constitucional es algo más que gobernar con una Constitución, significa gobernar «con arreglo a» normas constitucionales ${ }^{123}$. No me parece exagerado afirmar que, sin reformas periódicas, el Estado constitucional y el Estado de Derecho se ven resquebrajados. Pero esta afirmación no da respuesta a cuál sea la frecuencia deseable.

Constituciones rígidas e irreformables. Las ideas de rigidez y flexibilidad suelen utilizarse para señalar diferencias. Las constituciones pueden ordenarse conforme a los obstáculos formales a su enmienda. Pero esta distinción puede inducirnos a confusión ${ }^{124}$, como me temo que haya ocurrido, y creer que una constitución rígida es siempre de difícil modificación y se verá alterada con escasa frecuencia. Sin embargo, «rígida» no es lo mismo que «irreformable». Este extendido error de perspectiva, la confusión entre lo formal y lo sustantivo, entre procedimiento y contenido, se ha cometido durante décadas en España, al atribuirse a la rigidez de los artículos 167 y 168 la dificultad de las modificaciones ${ }^{125}$. El muy agravado segundo procedimiento está inspirado en la Constitución belga de $1831^{126}$ y ciertamente responde a la rigidez propia del primer liberalismo en esta cuestión

121 Idem, p. 85.

122 Idem, pp.103-104.

123 Idem, p.143.

124 Muy crítico se muestra WHEARE quien sostiene con una hipérbole que estas notas «inducen inevitablemente a error» y que la distinción adolece de indeterminación. Idem, p. 21.

125 Sin embargo, F. Rubio: «Rigidez y apertura...», ob.cit., p. 35, sostuvo que la dificultad «casi insalvable» para la reforma de la Constitución española «no deriva... de su rigidez sino paradójicamente de su apertura»: de la dificultad política de cerrar la constitución. Un planteamiento que comparto: una amplia apertura de la Constitución territorial y serias dificultades para un pacto constitucional hacen la reforma en España muy difícil.

126 J.C. SCHOLSEM: «La nueva Constitución belga» en Revista del Centro de Estudios Constitucionales, $\mathrm{n}^{\circ}$ 20, 1995, pp. 61-164, recuerda que esta Constitución fue muy estable y tuvo sólo dos revisiones hasta 1970, pero se sometió a cuatro revisiones de 1970 a 1993 por cuestiones federales. 
obsoleto. España sólo ha modificado dos veces su constitución en casi cuatro décadas y ambas por imperativos del Derecho de la Unión.

La frecuencia de la reforma no depende de la constitución sino de las condiciones materiales. Sin embargo, la modificación de una constitución no depende de sí misma sino de la presencia de unas condiciones materiales que hagan posible un momento constituyente. Las condiciones materiales de la España de 1977, cuando el diagnóstico sobre la necesidad de aprobar inmediatamente una constitución ya se compartía por la práctica totalidad de las fuerzas políticas, aunque no se conociera su conformación normativa, han desaparecido. Es hoy otro el sistema de partidos y aún no existen unas condiciones alternativas que hagan posible un pacto.

Razones para la rigidez y la estabilidad. Son muchas las circunstancias que producen constituciones rígidas según nos enseñó Bryce ${ }^{127}$. Enunciaba al deseo de los ciudadanos de asegurar sus derechos cuando los sienten amenazados. El deseo de cristalizar una forma de gobierno preexistente y evitar posteriores controversias respecto de la misma. El deseo de fundar una comunidad política nueva mediante un instrumento constitucional. El deseo de comunidades separadas o grupos distintos de colaborar y asegurar su acción conjunta en los asuntos comunes. Hasta aquí Bryce. Sin embargo, obsérvese que todas estas razones valen también para la revisión. Así ocurre con la garantía de los derechos sociales en tiempos de gran recesión económica, o con la mejora de la mala representación y la desafección de los jóvenes respecto de los partidos políticos, o con el pacto federal entre comunidades territoriales con conflictos, o con la necesidad de renovar los acuerdos intergeneracionales cuando los más jóvenes ya no recuerdan las claves originarias del pacto constitucional.

La tensión entre fuerzas centripetas y centrifugas. La mengua de la capacidad de adaptación o resiliencia constitucional. Si su fuerza centrípeta sigue siendo poderosa, una constitución no necesita modificarse con urgencia, los aspectos más técnicos y de detalle pueden esperar. Mas cuando la intensidad de las fuerzas centrífugas sobrepasa a la «resiliencia» de las fuerzas centrípetas, es decir, su capacidad de adaptación a las fuerzas adversas recuperando la situación de inicial de equilibrio en otro lugar, la necesidad de la revisión se hace inevitable, cuando menos si no desaparece la perturbación. La desaparición de la resiliencia constitucional marca el momento de la revisión de una constitución. Por eso una teoría especial de una constitución no puede ser abstracta sino concreta y debe estar ligada a los hechos y responder a la pregunta: ¿cuándo las fuerzas centrífugas amenazan seriamente una constitución? Claro está que existen otro tipo de reformas constitucionales sobre aspectos técnicos o de detalle que simplemente intentan mejorar las instituciones que amenazan deteriorarse. Son los usos normales de la reforma, esta labor de mantenimiento y revisión suele amortiguar y posponer la necesidad de otras reformas de mayor calado.

127 J. Bryce: Constituciones flexibles..., ob.cit., p. 69. 
¿Constituciones flexibles $y$ rígidas? Las constituciones flexibles cambian de forma imperceptible, mientras que las rígidas permanecen fijas y estables en su sitio decía Bryce quien explicaba que unas son fluidas y las otras sólidas; las constituciones flexibles tienen elasticidad y se adaptan sin perder sus características principales, las rígidas resisten la presión de viento o del agua ${ }^{128}$. Pero estas consideraciones pueden ser hoy discutibles. Las constituciones rígidas no tienen por qué no ser fluidas y actualizarse con frecuencia. A la par, la constitución flexible del Reino Unido no ha tenido tantas modificaciones esenciales en siglos ${ }^{129}$. En cambio, la constitución alemana es rígida y se ha reformado desde 1949 en una cincuentena de ocasiones, mucho más frecuentemente que la británica, flexible, histórica y sólo en parte escrita. La rigidez atiende a la autoridad suprema de las constituciones: a la previsión de un procedimiento de reforma con requisitos agravados, así como a la mayor jerarquía de la reforma que la ley ordinaria.

Constituciones dinámicas o estáticas: nuevas o viejas. Pero la revisión de una constitución depende de un conjunto de condiciones materiales mucho más que de su carácter rígido o flexible. Lucas Verdú ${ }^{130}$ lo advirtió bien cuando nos recordaba, citando a Duverger, que la constitución consuetudinaria francesa del Antiguo Régimen, pese a ser flexible, era muy estática, escasamente fluida y prácticamente inmodificable ${ }^{131}$. El propio Bryce conocía muy bien que la constitución romana cambió relativamente poco en tres siglos pese a que podía ser modificada

128 J. Bryce: Constituciones flexibles..., ob. cit., p.

129 La afirmación puede matizarse, y claro está depende del momento que se tome como punto de partida. Cuanto más nos alejemos en el tiempo, mayores son los cambios sobrevenidos. Así, en los siglos Xx y XXI, aunque se mantuviera la esencia del constitucionalismo británico se produjeron cambios relevantes: el sufragio universal, la reducción de los poderes de la Cámara de los Lores en 1911, o la regulación del estatuto de los ministros. Más recientemente, la devolución de poderes a Escocia y Gales y el régimen de Irlanda del Norte, la integración europea y el posterior Brexit, la integración en el sistema del Convenio Europeo mediante la Human Rights Act, y la creación de un Tribunal Supremo. Pero no creo que estos matices alteren la lógica de la afirmación de partida. Debe leerse R. BUSTOS: «La desnudez de la constitución británica. Crónica marciana de la sentencia de la Suprema Corte de Justicia del Reino Unido de 24 de enero de 2017» en Revista Española de Derecho Europeo, de próxima aparición, quien recuerda la sugerente tesis de RIDLEY: no hay realmente una constitución británica flexible sino un constitutional arrangement. El Reino Unido está desnudo y no maravillosamente vestido precisamente por carecer de un texto escrito, codificado y dotado de superioridad formal, no hay más superioridad que la del parlamento. Acabamos de verlo.

130 P. LuCAS verdú Prólogo a James Bryce: ob.cit, p. XXXVIIII, nota 60.

131 Que el Antiguo Régimen tuviera una constitución consuetudinaria e inmodificable no obsta a que fuera una constitucional nominal e incumplida constantemente en la realidad. Madame de Staël, la hija del Necker, —célebre Ministro de Luis XVI-, en sus elegantes Consideraciones sobre la Revolución francesa se preguntaba (Arpa, Barcelona, 2016, Capítulo XI, original en francés de 1818) si existía una constitución en Francia antes de la Revolución, una circunstancia que — estimaba - habría desprovisto de justificación a la misma. Pero tras recordar los argumentos de los informes de M. De Calone y M. De Monthion, concluía que muchos principios razonables de la constitución del Antiguo Régimen no habían sido respetados y cabía redactar una larga relación de abusos y arbitrariedades en Francia antes de la Revolución. Si no había constitución o se incumplía, la Revolución se hallaba justificada, aunque no así los excesos del terror, concluía. Deben recordarse también las afirmaciones más conocidas de Sieyès. 
fácilmente con «un voto de los comitia seguido del silencio de los tribunos» ${ }^{132}$. Creo pues más relevante distinguir entre Constituciones «dinámicas o estáticas», o lo que es lo mismo «nuevas o viejas», dentro una única familia contemporánea de Constituciones rígidas.

¿Cabe un Derecho constitucional viejo, codificado y estático? La pregunta es entonces qué sentido tienen codificar una constitución que no se renueva. El Derecho codificado debe ser revisado, por definición, de tiempo en tiempo como ilustra la experiencia de los códigos civiles desde el XIX. Esta es la virtud principal de toda codificación: la racionalidad y la seguridad jurídica que otorga su constante actualización. La lógica del constitucionalismo no puede desentenderse del resto de la codificación. Las constituciones rígidas deben ser igualmente fluidas o dinámicas y, en cierto sentido, flexibles. La diferencia es de grado.

La percepción de la necesidad de la reforma. Pero qué ocurre cuando las fuerzas políticas, sociales y económicas o, la correspondencia de las tres que suelen liderar los partidos políticos hasta que las situaciones se agravan, no perciben la utilidad de la reforma. ¿Cuándo no reformar una constitución suscita más problemas que reformarla? Bryce nos ofreció una respuesta «los únicos casos en que el desarrollo constitucional se detiene son aquellos en donde... una oligarquía se apodera del control del gobierno, y detiene, con la extinción del espíritu y los hábitos de libertad, los procesos naturales del movimiento y el desarrollo». Pero las constituciones — concluía - no pueden «apurarse hasta lo último» ${ }^{133}$.

La reforma recuerda al pueblo su soberanía: un ejercicio de democracia. Una constitución «ha brotado de la soberanía popular» y «recuerda al pueblo su propia soberanía» sostenía Bryce ${ }^{134}$ Cuando se produce desafección respecto de una constitución y mala representación política este argumento deviene central. La reforma constitucional permite al pueblo visualizar su propia soberanía frente al gobierno de unos pocos representantes. Toda democracia representativa es elitista, al venir fundada en elecciones, mientras la reforma apodera y fortalece al pueblo como verdadero sujeto de la democracia. Este rasgo concede relevancia a la reforma constitucional cuando la democracia representativa entra en crisis, precisamente porque permite revitalizar la democracia. El propio Bryce advertía del peligro del «enorme poderío que lo partidos han adquirido», «por lo cual la cabeza de cada gabinete puede llegar a creerse una especie de dictador, al recibir su autoridad... de la Cámara de los Comunes que es recibirla en realidad del llamado mandato directo de los electores ${ }^{135}$. Pero ese es el camino — decía- hacia el final del parlamentarismo y de la representación liberal y hacia la dictadura:

132 J. Bryce: Constituciones flexibles..., ob. cit., p. 27, quien publicó en 1864 The Holy Roman Empire, Mac Millan, Londres.

133 J. BRyCE: Constituciones flexibles..., pp. 25, por eso calificaba estas posiciones como de «estúpido conservadurismo» (p. 29).

134 Idem, p. 31.

135 Idem, p. 41. 
«reinar con el espíritu de un tirano bajo las formas de una constitución» ${ }^{136}$. Si las constituciones no se renuevan, se abre la puerta a las revoluciones o a la tiranía: a distintos grados de fórmulas autoritarias. ¿Puede un sistema de partidos, por su misma heterogeneidad y desavenencias, oponerse a la reforma que demande una amplia mayoría de la opinión pública? ¿Cuánto tiempo?

Los riesgos de una constitución estática o vieja. Una constitución es fruto de la historia de una nación y difícilmente puede situarse fuera de ella. Esto es manifiesto en el momento de su aprobación, pero no resulta tan evidente a la hora de su revisión. Algunos representantes suelen ir por detrás de los representados, ¿qué hay que conservar cuando las condiciones de la realidad social y la constitución formal ya no coinciden y no se reajustan? El tiempo convierte las constituciones en algo diferente a lo que vieron quienes presenciaron su infancia. Otro tanto ocurre con la adhesión de los ciudadanos a la constitución. El riesgo de una constitución estática es devenir una constitución obsoleta, un símbolo viejo y deteriorado que todavía se custodia, pero, en cuanto no se toca, ya no puede producir integración política.

Reforma o ruptura. ¿Cómo podemos conciliar un sistema constitucional con la tensión impulsada por nuevas fuerzas sociales? Hay constituciones que magnifican o maximizan las normas originarias, como son los ejemplos de Estados Unidos y México, dado su apoyo en la historia y en la opinión pública al resultar un precipitado de procesos revolucionarios. Pero hay otras muchas que se renuevan frecuentemente como Alemania o Francia y muchos países europeos y latinoamericanos. Mas si la reforma no se produce, antes o después sobrevienen las mutaciones que ponen a prueba la elasticidad de la constitución, o, con mayor gravedad, las rupturas.

La frecuencia de la reforma: bent o broken ${ }^{137}$. Una constitución flexible, por su elasticidad, no necesita ser reformada con tanta frecuencia como una constitución rígida, ya que a causa de su estructura «menos cohesionada y soldada» puede doblegarse sin romperse, puede ser «retorcida y estirada», hasta que el carácter de la comunidad cambie completamente y ya no existen previsiones normativas para los nuevos $\operatorname{casos}^{138}$. El valor de la elasticidad estriba en que proporciona los medios necesarios para prevenir o reducir al mínimo las revoluciones saliendo al paso del problema a mitad del camino ${ }^{139}$. Nada de esto puede decirse de las constituciones rígidas. Pero «la experiencia de que una constitución es modificable sin gran esfuerzo, ayuda a la creación de partidos revolucionarios menos violentos y partidos reaccionarios menos tercos, dispuestos siempre a llegar a un compromiso» ${ }^{140}$

136 Idem, p. 42.

137 La dicotomía la expresa el propio J. BRYCE: The American Commonwealth, ob.cit., p. 390: «Even the Constitution we call rigid must make their choice between being bent or being broken».

138 J. BRyCE: Constituciones flexibles..., pp. 32, 33 y 37

139 Idem, p. 36.

140 Idem, p. 37. 
Frecuencias mínima y máxima. Cuál es la frecuencia aconsejable para el recto funcionamiento de una constitución. ¿Dos veces en treinta y cinco años como en España? ¿Más de seiscientas veces como en México? Una frecuencia mínima puede acabar devaluando la normatividad constitucional y privando de eficacia al texto constitucional que no se adapta a la realidad. Una frecuencia máxima merma la autoridad de las normas constitucionales y acaba confundiéndolas con las leyes, y por ello igualmente devalúa su valor normativo. Los cambios constitucionales no deben ser fáciles, por definición, o no tan fáciles como las modificaciones legislativas, pero tampoco insólitos e infrecuentes. No es prudente «una transformación rápida y atolondrada de las instituciones fundamentales» por acciones parlamentarias ${ }^{141}$ decía Bryce.

Pequeños cambios continuos. Bryce sugería «pequeños cambios continuos» ninguno de los cuales haga que el sistema parezca «sustancialmente diferente», pues «lo añadido como nuevo era muy poco en relación con lo mucho que quedaba de lo antiguo» ${ }^{142}$. Ponía como ejemplos la limitación de la prerrogativa real y la extensión del sufragio de unos pocos a la multitud. Pero qué ocurre cuando las constituciones no se revisan fluidamente, desaparece la capacidad de compromiso entre los partidos y el ejercicio de la soberanía popular no se percibe con facilidad, la facultad de integración que toda constitución debe dispensar se ve aminorada y también su capacidad de solución de conflictos. Surgen entonces fuerzas que se aferran y apuran las constituciones, y fuerzas revolucionarias que pretenden cambiarla por otras desde nuevos procesos constituyentes. La ausencia de revisión de las constituciones no es sino un lento suicidio que antes o después puede terminar con un ordenamiento constitucional. Adolfo Posada reflexionó sobre la pasividad en la reforma de la Constitución de 1876, pero la reforma jamás se produjo y sobrevino primero la Dictadura y luego la proclamación de la II República y una nueva Constitución muy distinta en $1931^{143}$.

Puede concluirse que la reforma es una obligación positiva y un ingrediente esencial del concepto de constitución normativa a causa de la lógica propia de la continuidad de los ordenamientos jurídicos y del dinamismo inherente a toda normalidad o realidad constitucional. Las constituciones pueden desaparecer como normas por la inacción del poder de reforma.

141 Idem, p. 41.

142 Idem, p. 38.

143 A. Posada: La reforma constitucional, Librería General de Victorino Suarez, Madrid, 1931, decía que la eficacia de una constitución depende del acierto con que se haya sabido interpretar «la capacidad asimiladora de un pueblo» y las fuerzas que mueven su voluntad (p. VI) y censuraba la responsabilidad de la «vieja política» (capítulo III). M. GARCía CANALES: "Los intentos de reforma de la Constitución de 1876» en Revista de Derecho Político, n 8, 1981, pp. 113-135, dirá que esa Constitución nació del miedo al pasado y murió de inacción. Las constituciones pueden desaparecer por la inacción del poder de reforma. 


\section{PLURALISMO DE CONSTITUCIONES: EL IMPACTO DEL CONSTITUCIONALISMO DE LA INTEGRACIÓN.}

Procesos supranacionales de integración y vaciamiento de las constituciones. Los actuales escenarios de pluralismo de constituciones ${ }^{144}$ están cambiando nuestras constituciones nacionales y deben producir consecuencias en la teoría de la reforma constitucional. Es determinante calibrar el fuerte impacto transformador del Derecho de la Unión Europea y del Consejo de Europa en las constituciones internas. Dos procesos de integración europea, una inicialmente económica y otra a través de derechos, cuyas consecuencias deben aflorar expresamente en las normas constitucionales, si no queremos que las leyes fundamentales pierdan legitimidad democrática y se produzcan desajustes en la división de poderes internas y una peligrosa desaparición de controles democráticos. Si la aprobación del presupuesto se ha ido en una corriente hacia arriba hacia la constitución europea, algo debería preverse en ese mismo momento en que cambia el Derecho de la Unión y en los dos lugares: las constituciones formales de los Estados y la constitución material europea. Tampoco puede transferirse la soberanía monetaria, el euro y la dirección de la política monetaria a la Unión y que tal vaciamiento de las facultades del Gobierno no deje huella expresa alguna en la constitución interna ${ }^{145}$. Si esta labor de pedagogía constitucional y legitimidad democrática que las reformas constitucionales cumplen no se atiende con simultaneidad y diligencia en cada escalón de la integración europea, y los Gobiernos se limitan a actuar al remolque de la Unión y con simple inercia, fenómenos nacionalistas y pasionales pueden aparecer antes o después y acabar rompiendo los procesos de integración como ha ocurrido con el Brexit. Los cambios constitucionales derivados de la integración europea deben anunciarse y asumirse lentamente, y explicarse a la opinión pública, y reflejarse en nuevas normas constitucionales en los dos niveles. Las constituciones formales deben adecuarse a estas realidades, moldearse antes de quebrarse, y reflejar los hitos de esos procesos.

¿Antinomias constitucionales? No menos relevante, aunque de diverso tipo, es el impacto transformador de las decisiones del Tribunal Europeo de Derechos Humanos y de la Corte Interamericana de Derechos Humanos que están fortaleciendo una identidad europea y latinoamericana. Crear o consolidar antinomias constitucionales ${ }^{146}$ entre los mandatos constitucionales internos y las normas supranacionales, negándose a asumir reformas constitucionales obligadas por las normas

144 Vid, entre nosotros, R. Bustos: La Constitución red: un estudio sobre supraestatalidad y Constitución, IVAP, Oñati, 2005. Es clásico sobre el pluralismo constitucional, N. MACCORMICK: Questioning sovereignty. Law, state, and nation in the European Commonwealth, Oxford University Press, 1999.

145 Véase J. García Roca y M.A. Martínez LAGO: «El impacto de la crisis económica en nuestras dos constituciones» en Documentación Administrativa, $\mathrm{n}^{\circ} 1,2104$.

146 Recordemos que la Constitución suiza (artículos 193.4 y 194.2) impide acertadamente violar las normas imperativas de Derecho Internacional mediante la reforma total o parcial. 
convencionales, es ubicar a ciudadanos y poderes públicos en un callejón sin salida ${ }^{147}$. Porque, por definición, los sistemas de protección supranacional de derechos no pueden detener sus controles ante las constituciones nacionales en defensa de los derechos de las personas por más que deban ser especialmente prudentes y deferentes en ciertas ocasiones respetando un margen de discrecionalidad y diferen$\mathrm{cia}^{148}$. En todo caso, ambos sistemas mantienen permanentemente actualizadas las declaraciones nacionales de derechos que ya no pueden ser cerradas — no suelen serlo en Latinoamérica ${ }^{149}$ — sino abiertas al Derecho Internacional de los derechos.

Un bloque de la constitucionalidad-convencionalidad. Como corolario, la interpretación conforme de los derechos constitucional y convencionalmente reconocidos está creando por fusión un bloque de la constitucionalidad-convencionalidad difícilmente escindible y una europeización o americanización de las jurisdicciones constitucionales. Este es el futuro. Pero ese es ya un nuevo artículo y debo detenerme aquí.

\section{CONSIDERACIONES FINALES.}

Los primeros modelos liberales se excedieron en su prudencia al regular los procedimientos de reforma. El constitucionalismo democrático debe seguir requisitos más accesibles y desdramatizar la reforma: hacerla un instrumento normalizado. La reforma es una obligación positiva, un ingrediente esencial del concepto de constitución, debido a la lógica de la continuidad del Estado ${ }^{150}$ y al dinamismo inherente a toda realidad. No hay otra manera de hacer compatibles normalidad y normatividad constitucionales.

Pero la reforma de una constitución formal no depende de sí misma ni siquiera de la rigidez que explicita un procedimiento de reforma sino de la existencia de unas condiciones materiales adecuadas en la realidad política. Rígida no es lo mismo que irreformable en cuanto atributos de una constitución. No cabe la confusión entre lo formal y lo sustantivo, entre procedimiento y contenido. Cuando el impulso de las fuerzas centrífugas sobrepasa la resiliencia constitucional, su

147 J.L. REQUEJO recuerda que el Estado nacional europeo ya no es el escenario de poder que importa. Los propios Estados iniciaron la creación de un nuevo soberano al poner en marcha las Comunidades. Las dimensiones constitucionales son las del continente. El sueño constitucional, KRK, Oviedo, 2016. También S. MuÑoz MACHADO. ob.cit., epígrafe «La cosmópolis europea. El ejemplo de los derechos fundamentales», p. 264 y ss, se refiere a cómo un nuevo orden constitucional complementa y en ocasiones se sobrepone al constitucionalismo estatal.

148 Cfr J. García Roca y E. Carmona: ¿Hacia una globalización de los derechos». El impacto de las sentencias del Tribunal Europeo y de la Corte Interamericana, Thomson Reuters Aranzadi, Madrid, 2017.

149 Así la Const. argentina (artículo 33) precisa que las declaraciones de derechos y garantías que enumera no pueden ser entendidos como negación de otros no enumerados.

150 La conexión la establece M. Hauriou: Principios de Derecho Público y Constitucional, Reus, Madrid, 1927, traducción de C. Ruiz del Castillo, p. 322 y ss. 
capacidad de adaptarse con flexibilidad a la realidad, y al poder unitario de las fuerzas centrípetas, la necesidad de la revisión se hace inevitable. La desaparición de la resiliencia constitucional marca el momento de la revisión de una constitución.

Pero el problema central en la reforma constitucional escapa al mundo del Derecho: la capacidad de una mayoría parlamentaria de encontrar aliados y erigir un pacto constitucional.

La reforma constitucional es una decisión política. Explicar adecuadamente las modificaciones a la opinión pública y medir el tempo de ejecución de la pieza son labores difíciles. Es imprescindible una tramitación parlamentaria que permita alcanzar compromisos y mayorías cualificadas a través de la deliberación y la participación. El poder de reforma es constituido y por ello el referendo no resulta indefectible si la cuestión no afecta a decisiones políticas básicas; ésta es la tendencia del Derecho Constitucional comparado.

No tiene mucho sentido mantener como nuclear en el siglo XXI —en vez de simplemente como propedéutica- la distinción entre constituciones flexibles y rígidas, ya que apenas existen términos de comparación en el primer lado. Las constituciones escritas son rígidas. Además, las constituciones rígidas no tienen por qué no reformarse con frecuencia, mientras algunas de las flexibles apenas han sufrido modificaciones. La verdadera distinción en el constitucionalismo actual debe producirse entre constituciones dinámicas y estáticas, según se revisen periódicamente o no, o, lo que es lo mismo, entre constituciones nuevas y viejas dentro una única familia de constituciones rígidas.

Las constituciones viejas o estáticas tienden a ser simbólicas y dejan su especificación en mutaciones en las manos de los jueces o en actuaciones de los órganos constitucionales por simple vía de hecho, lo que les hace perder legitimidad democrática y acaba por deteriorar el Estado de Derecho. Las constituciones dinámicas y nuevas son verdaderamente normativas, rigen la realidad constitucional, y vienen dotadas de una mayor legitimidad democrática, permiten vivir «en» constitución.

Me pregunto qué sentido tiene codificar una constitución que no se renueva, cuando la virtud principal de toda codificación es la racionalidad que otorga su constante actualización. Las constituciones no pueden apurarse. El riesgo de una constitución estática es devenir vieja, un símbolo deteriorado que todavía se custodia, pero ya no produce integración política o no regula realmente como norma las nuevas realidades.

La reforma se vertebra en un pacto constitucional y recuerda al pueblo su soberanía; es una sana práctica democrática que dispensa legitimidad democrática, revitaliza el parlamentarismo, y permite ejercer la participación y la representación.

Las reformas constitucionales no deben ser fáciles, por definición, o no tan fáciles como las modificaciones legislativas, pero tampoco insólitas. No es prudente una transformación rápida y atolondrada de las instituciones, lo ideal son pequeños cambios periódicos ninguno de los cuales haga que el sistema parezca 
sustancialmente diferente. Pero cada país hace lo que puede y donde no existe una cultura de la negociación y el acuerdo tampoco puede haber una cultura de la reforma constitucional.

Los actuales escenarios de pluralismo de constituciones e integración europea y latinoamericana están transformando nuestras constituciones nacionales y deberían tener consecuencias expresas mediante correlativas reformas constitucionales en los dos niveles de gobierno al mismo ritmo de la evolución del proceso.

\section{$* * *$}

TITLE: «On Constitutional review: new and old constitutions».

ABSTRACT: Liberal constitutionalism has been too cautious in regulation of constitutional reform proceedings. Democratic constitutionalism should follow easier requirements and simple procedures. It is necessary to normalise constitutional reform as an ordinary tool. However, constitutional review does not depend on legal rigidity but on certain material conditions that make reforms possible. When constitutional resilience disappears the moment of the reform seems to have arrived. Yet this is not a legal issue, but depends on the capacity of a majority to gain allies in order to reach a constitutional arrangement. Reform is always a political decision. However, legal proceedings require qualified majorities, democratic deliberation and political engagement, but being the reform a pouvoir constitue a referendum is not always necessary, if essential political decisions are not involved. Written constitutions are nowadays rigid, the true difference comes between new and old constitutions. Old or static constitutions are symbolic and leave their development either to judicial review, or even to some forced interpretations by public powers or the impact of simple facts in realities. Constitutional reform reminds citizens their popular sovereignty and strengthens representative democracy. Nevertheless, in those countries were a culture of negotiation does not exist, a culture of constitutional reform cannot exist too. The present-day scenario of multilevel constitutional pluralism is transforming domestic constitutions, and this phenomenon must have consequences in the promotion of regular internal constitutional reforms at the same rhythm as the advance of supranational integration.

RESUMEN: El liberalismo fue demasiado prudente al regular los procedimientos. El constitucionalismo democrático debe seguir requisitos más accesibles y desdramatizar la reforma como una herramienta ordinaria. Pero la cuestión no depende de la rigidez sino de unas condiciones materiales que hagan posible la reforma. Rígida no es irreformable. La desaparición de la resiliencia constitucional marca el momento de la reforma. Sin embargo, este problema central no es jurídico: la capacidad de una mayoría de encontrar aliados y erigir un pacto constitucional. La reforma es una decisión política. La tramitación demanda mayorías cualificadas, deliberación y participación, pero el poder de reforma es constituido y el referendo no resulta indefectible, si la cuestión no afecta a decisiones políticas básicas. Las constituciones escritas son hoy rígidas: la verdadera distinción surge entre constituciones nuevas y viejas. Las viejas o estáticas son simbólicas y dejan su especificación a mutaciones judiciales, interpretaciones manipuladoras o a vías de hecho. La reforma recuerda al pueblo su soberanía y revitaliza la democracia representativa; mas donde no existe una cultura de la negociación tampoco puede haberla de la reforma. El escenario de pluralismo de constituciones está transformando nuestras constituciones nacionales y debería tener consecuencias en correlativas reformas constitucionales al ritmo en que avanza la integración supranacional.

KEY WORDS. Constitutional reform, constitutional review, constitutional reform proceedings, rigid and flexible constitutions, constitutional arrangement or agreement, constitutional resilience, parliamentary majorities, deliberative democracy and referendum, new and old constitutions, constitutional pluralism. 
Palabras clave. Reforma constitucional, revisión de las constituciones, procedimientos de reforma, Constituciones flexibles y rígidas, pacto constitucional, resiliencia constitucional, mayorías parlamentarias, democracia deliberativa y referéndum, Constituciones nuevas y viejas, pluralismo de constituciones.

FECHA DE RECEPCIÓN: 17.04.2017

FECHA DE ACEPTACIÓN: 26.07.2017 